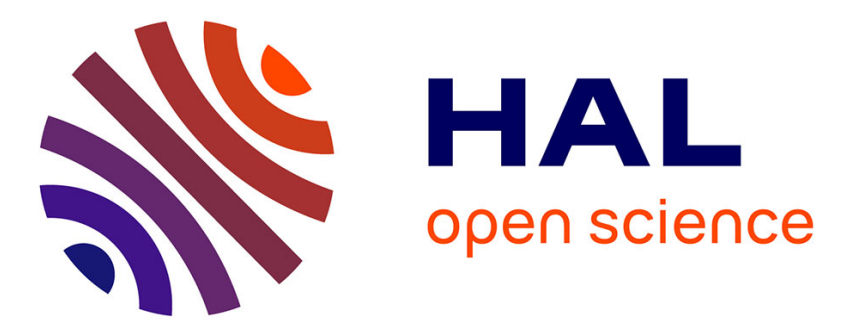

\title{
Dislocation-based model for the prediction of the behavior of b.c.c. materials - grain size and strain path effects
}

Tales Carvalho Resende, Salima Bouvier, Farid Abed Meraim, Tudor Balan, Simon Serge Sablin

\section{To cite this version:}

Tales Carvalho Resende, Salima Bouvier, Farid Abed Meraim, Tudor Balan, Simon Serge Sablin. Dislocation-based model for the prediction of the behavior of b.c.c. materials - grain size and strain path effects. International Journal of Plasticity, 2013, 47, pp.29-48. 10.1016/j.ijplas.2013.01.003 . hal-01191889

\section{HAL Id: hal-01191889 \\ https://hal.science/hal-01191889}

Submitted on 2 Sep 2015

HAL is a multi-disciplinary open access archive for the deposit and dissemination of scientific research documents, whether they are published or not. The documents may come from teaching and research institutions in France or abroad, or from public or private research centers.
L'archive ouverte pluridisciplinaire HAL, est destinée au dépôt et à la diffusion de documents scientifiques de niveau recherche, publiés ou non, émanant des établissements d'enseignement et de recherche français ou étrangers, des laboratoires publics ou privés. 


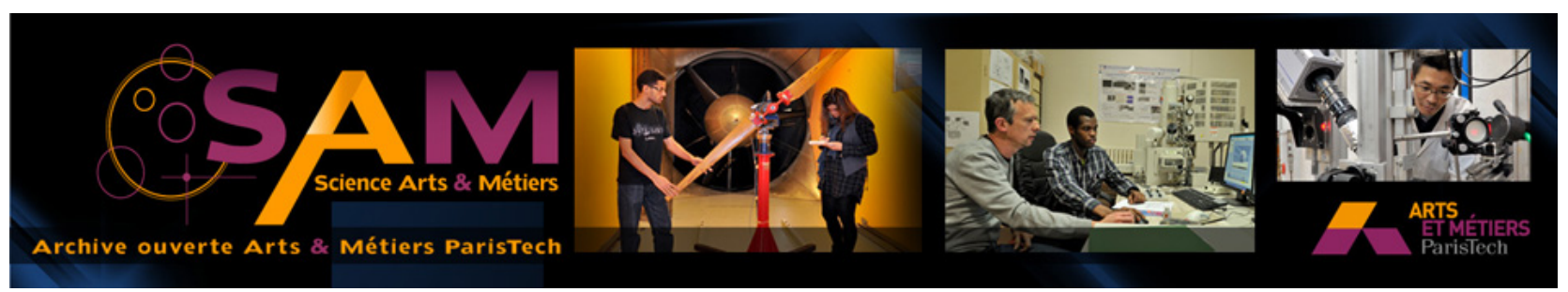

\section{Science Arts \& Métiers (SAM)}

is an open access repository that collects the work of Arts et Métiers ParisTech researchers and makes it freely available over the web where possible.

This is an author-deposited version published in: http://sam.ensam.eu

Handle ID: .http://hdl.handle.net/10985/9893

\section{To cite this version :}

Tales CARVALHO RESENDE, Salima BOUVIER, Farid ABED MERAIM, Tudor BALAN, Simon Serge SABLIN - Dislocation-based model for the prediction of the behavior of b.c.c. materials grain size and strain path effects - International Journal of Plasticity - Vol. 47, p.29-48 - 2013 


\title{
Dislocation-based model for the prediction of the behavior of b.c.c. materials - grain size and strain path effects
}

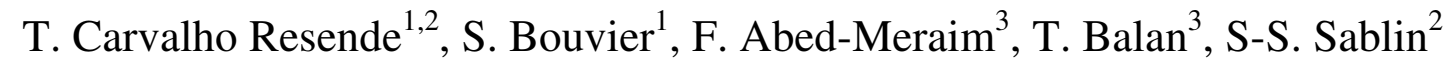 \\ ${ }^{1}$ Laboratoire Roberval, UMR CNRS 6253, Université de Technologie Compiègne, Centre de \\ Recherches de Royallieu, BP 20529-60205 Compiègne cedex, France \\ ${ }^{2}$ TECHNOCENTRE RENAULT - Vehicle Engineering - Materials Engineering Department - 1 \\ avenue du Golf, 78288 Guyancourt cedex, France
}

${ }^{3}$ Laboratoire d'Etude des Microstructures et de Mécanique des Matériaux, UMR CNRS 7239, Arts et Métiers ParisTech, 4 rue Augustin Fresnel, 57078 Metz cedex 03, France

tales.carvalho.resende@gmail.com, salima.bouvier@utc.fr, tudor.balan@ensam.eu, Farid.ABEDMERAIM@ensam.eu, simon-serge.sablin@ renault.com

Corresponding author : Pr Salima BOUVIER, Tel. +33 (0)3 4423 79 38, Fax +33 (0)3 44234984

\begin{abstract}
Sheet metal forming processes involve multi-axial strain paths. For the numerical simulation of such processes, an appropriate constitutive model that properly describes material behavior at large strain is required. For accurate and time-effective simulations, it is crucial to use plasticity models based on physics, as material macroscopic behavior is closely related to the evolution of the associated microstructures. Accordingly, a large strain work-hardening phenomenological model that incorporates the intragranular microstructure evolution through a dislocation density approach is proposed. The model is defined by a yield criterion and hardening laws that are all grain-size dependent. The classical Hill criterion in which grainsize dependency was introduced is proposed. Hardening laws are given by a combination of kinematic and isotropic contributions that respectively take into account the evolution with strain of cell blocks formed by geometrically necessary boundaries (GNBs) and individual dislocation cells delineated by incidental dislocation boundaries within cell blocks (IDBs). On the one hand, IDBs evolution contribution is described by a modified Rauch et al. isotropic model, which is able to describe work-hardening stagnation and work-softening. On the other hand, GNBs evolution contribution is described by a grain-size dependent tensorial backstress expression proposed by Aouafi et al. [2007] to describe the plastic anisotropy and Bauschinger effect. Moreover, the proposed model aims to accurately predict steel behavior through an innovative approach by only changing few "simply measurable" microstructure data (e.g. chemical composition, grain size...). The predictive capabilities of the model are assessed for interstitial free (IF) and dual phase (DP) steels with grain sizes varying respectively in the $8-40 \mu \mathrm{m}$ and $1-10 \mu \mathrm{m}$ value range. Different loading paths are analyzed, namely the uniaxial tensile test, reversal simple shear and orthogonal tests.
\end{abstract}


Keywords: A - Microstructures, A - Strengthening mechanisms, B - Constitutive behavior, A - Yield condition, B - Anisotropic material

\section{Introduction}

With a view to environmental, economic and safety concerns, car manufacturers need to design lighter and safer vehicles in ever shorter development times. In recent years, several mild steels such as interstitial free (IF) steels and high strength steels (HSS) as dual phase (DP) steels, are increasingly used for sheet metal parts in the automotive industry to reduce mass as they provide excellent drawability. The application of simulation models in sheet metal forming in the automotive industry has proven to be beneficial for reducing tool costs in the design stage and optimizing current processes. The finite element method (FEM) is quite successful to simulate metal forming processes, but the accuracy of such a tool depends on several important factors, such as the ability of the constitutive laws to describe material initial or induced anisotropy and work-hardening, especially after strain-path changes. Some effort is still required to improve the considered behavior models and to identify them in the most optimal way. These behavior models are generally separated in two categories: phenomenological approaches and physical descriptions. It is well-known that the main advantage of the phenomenological models is the rapidity in computation. Based on a consistent mathematical description of the observed macroscopic behavior, phenomenological models require fitting of material parameters involved in the constitutive equations on experimental results (see [Chaboche, 2008] for a general review). Such a process should be repeated for each material characterization. In many practical situations, these models provide effective tools and succeed in describing the material behavior depending on the complexity of the chosen functions. However, no direct physical links exist between the different scales embedded in these models.

Several experimental studies reported that the macroscopic behavior can be attributed to the evolution of the underlying microstructural details, such as dislocation structures (see, e.g., [Hasegawa and Yakou, 1974], [Fernandes and Schmitt, 1983], [Rauch and Schmitt, 1989], [Nesterova et al., 2001ab] among others). More physically based models are developed in order to take into account the consequence of the evolution of the dislocation structures on the macroscopic behavior and specifically when strain-path changes occur (see [Teodosiu and Hu, 1995], [Peeters et al., 2000], [Peeters et al., 2001a], [Yoshida and Uemori, 2002], [Yalcinkaya et al., 2009], among others). Nevertheless, the extensive computing time and resources required by such calculations represent some limitations that may prevent their use in finite element (FE) simulations of industrial forming processes. The goal of the present work is to develop a user-friendly and time-efficient phenomenological model that incorporates details of the microstructure evolution at the grain scale with a limited number of material parameters. Moreover, particular attention has been focused on keeping a strong physical relevance in describing a wide set of IF and DP steels and realistically reproducing the experimentally observed transients in the macroscopic behavior when strain-path changes occur. Furthermore, because the grain-size strengthening is meant to be the main contribution to work-hardening, an innovative approach that accurately estimates the macroscopic behavior of different steels by only changing few simply measurable microstructure data (i.e. 
chemical composition, volume fraction and grain size) is proposed. This strategy allows avoiding the time-consuming mechanical characterization and identification procedures once a set of fixed physically-based constant parameters is identified.

The outline of the paper is as follows. The macroscopic behavior of IF and DP steels is investigated in Section 2 by means of monotonic and sequential tensile and shear tests, and the underlying microstructural evolutions are analyzed. A dislocation-based constitutive model is derived in Section 3 that describes these evolutions. The parameter identification is addressed in Section 4. Due to the physical significance of several of the model parameters, it is not necessary to identify all of them for each new material, thus reducing significantly the cost of the identification procedure. Section 5 describes in detail the sensitivity of the model to each of these physically-based parameters in order to illustrate the flexibility of the model.

\section{Macroscopic behavior and microstructure evolution}

\subsection{Materials}

This study focuses on IF and DP steels with deep drawing quality. IF steels have been designed specifically for automotive applications. These steels are particularly suitable for structural (e.g. longitudinal beams, cross members, B-pillars) and closure applications. They provide an interesting combination in terms of drawability and mechanical strength. These steels have low yield strength and high work-hardening capability. In order to increase both formability and strength, more advanced high strength steels (AHSS), such as dual phase (DP) steels were developed and rapidly became among the most used steels in the automotive industry. Their microstructure typically consists of a soft ferrite phase with dispersed islands of a hard martensite phase.

In the present work, four IF and seven DP steels have been selected and completed by other similar steels from the literature. Their chemical compositions (in \% weight) are presented in Table 1 and Table 2, respectively.

Table 1. IF steels chemical composition in \% weight.

\begin{tabular}{cccccccccc}
\hline Materials & Reference & $\mathrm{C}$ & $\mathrm{Mn}$ & $\mathrm{P}$ & $\mathrm{Nb}$ & $\mathrm{Si}$ & $\mathrm{Cu}$ & $\mathrm{Ti}$ & $\mathrm{N}$ \\
\hline IF I & $\begin{array}{c}\text { [Uenishi and } \\
\text { Teodosiu, 2003] }\end{array}$ & 0.0016 & 0.10 & 0.005 & - & $\mathrm{N} / \mathrm{A}$ & - & 0.015 & 0.0018 \\
IF II & $\begin{array}{l}\text { [Uenishi and } \\
\text { Teodosiu, 2003] }\end{array}$ & 0.0013 & 0.97 & 0.005 & - & 0.014 & - & 0.014 & 0.0018 \\
IF III & $\begin{array}{l}\text { [Uenishi and } \\
\text { Teodosiu, 2003] }\end{array}$ & 0.0015 & 1.92 & 0.004 & - & 0.99 & - & 0.023 & 0.0018 \\
IF IV & [3DS, 2001] & - & - & - & - & - & - & - & - \\
IF V & [Cashform, 2001] & 0.006 & 0.16 & 0.005 & - & 0.0015 & N/A & 0.038 & - \\
\hline
\end{tabular}




\begin{tabular}{lcccccccccc}
\hline IF VI & 0.007 & 0.066 & 0.011 & - & 0.006 & 0.002 & 0.048 & - \\
IF VII & 0.007 & 0.255 & 0.019 & 0.0005 & 0.007 & 0.007 & 0.001 & - \\
& & & & & & & & \\
IF VIII & 0.06 & 0.727 & 0.013 & - & 0.074 & 0.008 & 0.001 & - \\
IF IX & 0.072 & 1.063 & 0.015 & 0.012 & 0.122 & 0.003 & 0.001 & - \\
\hline
\end{tabular}

Table 2. DP steels chemical composition in \% weight.

\begin{tabular}{cccccccccc}
\hline Materials & & $\mathrm{C}$ & $\mathrm{Mn}$ & $\mathrm{P}$ & $\mathrm{Nb}$ & $\mathrm{Si}$ & $\mathrm{Cu}$ & $\mathrm{Ti}$ & $\mathrm{N}$ \\
\hline DP I & DP 450 & 0.039 & 1.241 & 0.016 & 0.0008 & - & 0.005 & 0.002 & - \\
DP II & DP 600 & 0.115 & 1.391 & 0.012 & - & 0.347 & 0.007 & 0.010 & 0.0047 \\
DP III & DP 600 & 0.071 & 1.019 & 0.043 & 0.0013 & - & 0.008 & 0.003 & - \\
DP IV & DP 600 & 0.074 & 1.849 & 0.024 & 0.001 & - & 0.009 & 0.002 & - \\
DP V & DP 800 & 0.138 & 1.902 & 0.019 & 0.0012 & - & 0.011 & 0.019 & - \\
DP VI & DP 800 & 0.139 & 1.53 & 0.017 & 0.0011 & - & 0.012 & 0.003 & - \\
DP VII & DP 1000 & 0.067 & 2.55 & 0.014 & 0.0272 & - & 0.01 & 0.02 & - \\
DP VIII & DP 1000 & 0.092 & 2.485 & 0.017 & 0.0195 & - & 0.007 & 0.017 & - \\
\hline
\end{tabular}

\subsection{Microstructural evolution during monotonic, strain reversal and orthogonal loadings}

During deep drawing processes, rolled sheets are subjected to large plastic deformations and multi-axial strain paths, and the entire microstructure evolution can be hardly obtained experimentally. Hence, several studies [Fernandes and Schmitt, 1983], [Rauch and Schmitt, 1989], [Nesterova et al., 2001ab], [Gardey et al., 2005ab] have focused on reproducing some typical deep drawing strain paths through sequences of non proportional mechanical loadings. Such tests can be monotonic (tensile, shear tests) or series of different monotonic loadings (e.g. reverse or orthogonal strain-path changes...). In this context, the general macroscopic behavior for IF and DP steels is similar to results depicted in [Haddadi et al., 2006].

Explicitly, during strain reversal, IF steels exhibit a strong Bauschinger effect as well as work-hardening stagnation. These characteristic transient effects are followed by resumption of the work-hardening. The latter is related to microstructural evolution given that the initial microstructures are free of organized patterns for annealed materials [Nesterova et al., 2001a]. During monotonic deformation, dislocations arrange themselves into planar polarized dense dislocation boundaries called dislocation walls (DWs). DWs are more or less parallel to the main slip plane and divide the grains into cells [Nesterova et al., 2001a,b], [Franz et al. 2009]. During strain reversal, a stronger Bauschinger effect is observed on DP steels. Two reasons may explain such macroscopic behavior. The presence of the hard phase delays the dislocation patterning, which makes them less difficult to disintegrate. Moreover, the martensite hard phase introduces additional internal stresses because of its contrasting behavior compared to the ferrite phase. Slip systems that were active during pre-strain remain active after strain reversal but in the opposite direction. Thus, preformed DWs partially 
disintegrate, causing work-hardening stagnation. This transient behavior is more pronounced in IF steels than in DP steels. The formation of new DWs is responsible for work-hardening resumption after stagnation [Rauch and Schmitt, 1989]. After orthogonal loading, contrarily to IF steels, work-softening is absent in DP steels, which is related to the fact that MicroBands (MBs) are absent in the latter case [Gardey et al., 2005b]. A simplified summary of the presented microscopic features and their macroscopic counterparts is given in Table 3.

Table 3. Simplified summary of microscopic features and their macroscopic counterparts for IF and DP steels for low-to-intermediate strain.

\begin{tabular}{cccc}
\hline Microscopic feature & Macroscopic counterpart & IF steels & DP steels \\
\hline Formation of DWs & Work-hardening & Yes & Yes \\
Partial dissolution of polarized DWs & Bauschinger effect (BE) & Yes & Yes \\
Partial dissolution of polarized DWs & Work-hardening stagnation & Yes & Yes \\
Formation of MBs & Work-softening (WS) & Yes & No \\
\hline
\end{tabular}

\section{Experimental procedure}

Uniaxial tensile tests were performed in quasi-static regime at room temperature with a constant strain rate in a tensile machine INSTRON 5582 with an HRD extensometer system monitored by Bluehill@2 software. The obtained results are presented in Figure 1, where the true stress is plotted versus plastic true strain. The elastic strain part is removed using an offset of $0.1 \%$ plastic strain.
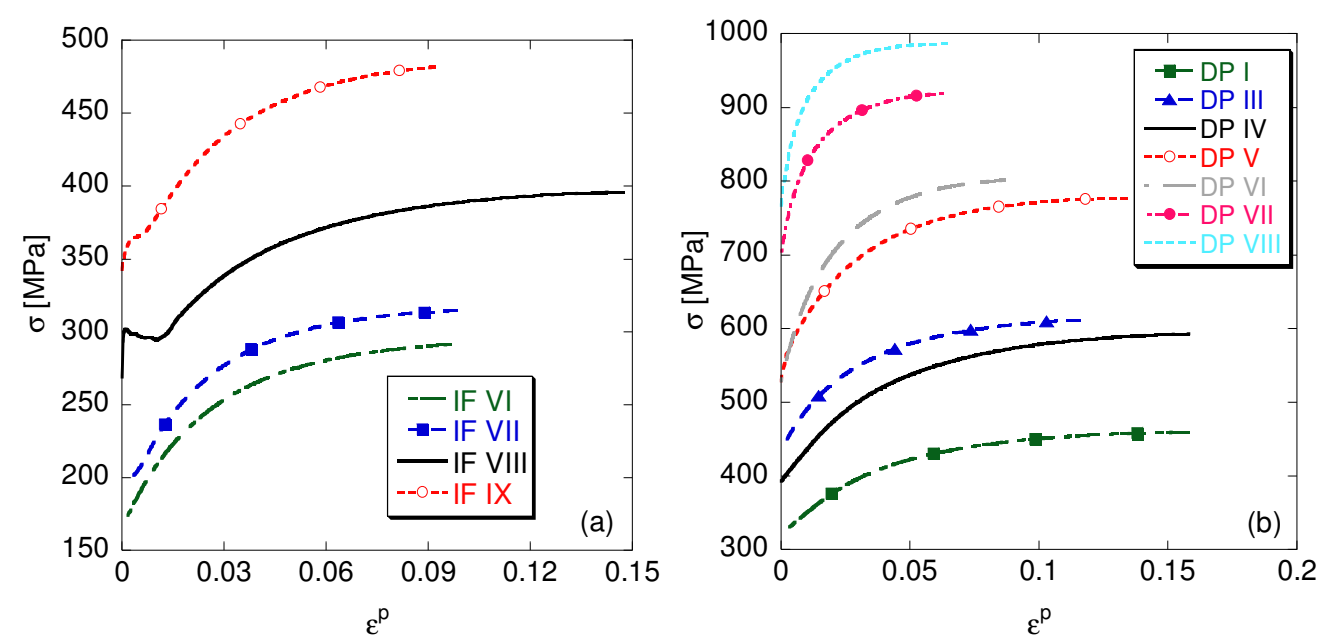

Figure 1. Uniaxial tensile tests ( $0^{\circ}$ to RD) performed on (a) IF steels and (b) DP steels.

In order to describe the initial yield surface, Lankford coefficients $r$-values are determined from uniaxial tensile test specimens cut out at different orientations, $0^{\circ}, 45^{\circ}$ and $90^{\circ}$ to the 
rolling direction of sheet. The $r$-values are calculated at a certain longitudinal strain (15$20 \%$ ) and an average value is used. Planar anisotropy is therefore given by:

$$
r_{m}=\frac{r_{0^{\circ}}+2 r_{45^{\circ}}+r_{90^{\circ}}}{4}
$$

The experimental results are indicated in

Table 4 and Table 5.

Table 4. IF steels grain sizes and standard deviations.

\begin{tabular}{lcccccccc}
\hline Materials & $Y_{0}$ & $\begin{array}{c}R_{m} \\
(\mathrm{MPa})\end{array}$ & $r_{0^{\circ}}$ & $r_{45^{\circ}}$ & $r_{90^{\circ}}$ & $r_{m}$ & $\begin{array}{c}D_{F} \\
(\mu \mathrm{m})\end{array}$ & $\begin{array}{c}\sigma_{D_{F}} \\
(\mu \mathrm{m})\end{array}$ \\
\hline IF I & - & - & - & - & - & - & 40 & - \\
IF II & - & - & - & - & - & - & 40 & - \\
IF III & - & - & - & - & - & - & 40 & - \\
IF IV & 121 & - & 2.53 & 1.84 & 2.72 & 2.23 & 25 & - \\
IF V & 113 & - & - & - & - & - & 25 & - \\
IF VI & 159 & 286 & 2.33 & 1.63 & 2.52 & 2.03 & 22 & 17 \\
IF VII & 200 & 314 & 1.82 & 1.12 & 1.9 & 1.49 & 15 & 13.5 \\
IF VIII & 300 & 393 & 0.84 & 1.01 & 1.02 & 0.97 & 10.5 & 9 \\
IF IX & 342 & 483 & 0.64 & 1.26 & 0.96 & 1.03 & 8 & 7 \\
\hline
\end{tabular}

Table 5. DP steels ferrite $\left(D_{F}\right)$ and martensite $\left(D_{M}\right)$ grain sizes. $V_{M}$ stands for martensite volume fraction.

\begin{tabular}{lcccccccccccc}
\hline Materials & & $\begin{array}{c}Y_{0} \\
(\mathrm{MPa})\end{array}$ & $\begin{array}{c}R_{m} \\
(\mathrm{MPa})\end{array}$ & $r_{0^{\circ}}$ & $r_{45^{\circ}}$ & $r_{90^{\circ}}$ & $r_{m}$ & $\begin{array}{c}D_{F} \\
(\mu \mathrm{m})\end{array}$ & $\begin{array}{c}\sigma_{D_{F}} \\
(\mu \mathrm{m})\end{array}$ & $\begin{array}{c}D_{M} \\
(\mu \mathrm{m})\end{array}$ & $\begin{array}{c}\sigma_{D_{M}} \\
(\mu \mathrm{m})\end{array}$ & $V_{M}$ \\
\hline DP I & DP 450 & 315 & 460 & 0.98 & 0.76 & 1.34 & 0.96 & 9 & 7.5 & 9.5 & 8 & 0.25 \\
DP II & DP 600 & 285 & - & - & - & - & - & 10 & - & 3.5 & - & 0.2 \\
DP III & DP 600 & 409 & 612 & 0.74 & 0.93 & 0.8 & 0.85 & 4 & 3 & 3 & 2.5 & 0.1 \\
DP IV & DP 600 & 393 & 593 & 0.94 & 0.84 & 1.39 & 1 & 6.5 & 4.5 & 2 & 1.5 & 0.2 \\
DP V & DP 800 & 530 & 776 & 0.77 & 1 & 0.86 & 0.91 & 3 & 2.5 & 2.5 & 2 & 0.2 \\
DP VI & DP 800 & 530 & 802 & 0.76 & 0.82 & 0.98 & 0.85 & 3 & 2 & 1.5 & 1 & 0.15 \\
DP VII & DP & 700 & 924 & 0.68 & 0.97 & 0.9 & 0.88 & 1.5 & 1 & 1.5 & 1 & 0.1 \\
& 1000 & & & & & & & & & & & \\
DP VIII & DP & 700 & 986 & 0.58 & 1.09 & 0.75 & 0.88 & 7 & 5 & 3.5 & 3 & 0.1 \\
\hline
\end{tabular}

Simple and reversal shear tests were performed in the rolling direction (RD) at equivalent conditions in a SERMEES shear assembly implanted in a tensile machine INSTRON 5587. These tests consist of subjecting flat samples to parallel displacements by fixing the lateral parts (Figure 2). Simple shear tests present the main advantages of reaching high homogeneous strain levels through simple sample geometry for flat parts. Reversing the load direction during the course of the experiment allows capturing the Bauschinger effect [Bouvier et al., 2006a]. Monotonic and reverse simple shear tests for different amounts of forward shear strain $\gamma_{T}\left(\gamma_{T}=2 \varepsilon_{12}\right)$ are performed. For simplicity purposes, the experimental results are reported in the same figures where the model predictions are indicated. An 
example of observed behavior is given in Figure 3 for each grade of material. The plots indicate shear stress $\tau=\sigma_{12}$ versus the plastic part $\gamma$ of the amount of shear strain. As for the uniaxial tensile test, the elastic part is removed using an offset of $0.1 \%$ von Mises equivalent plastic strain.

(a)

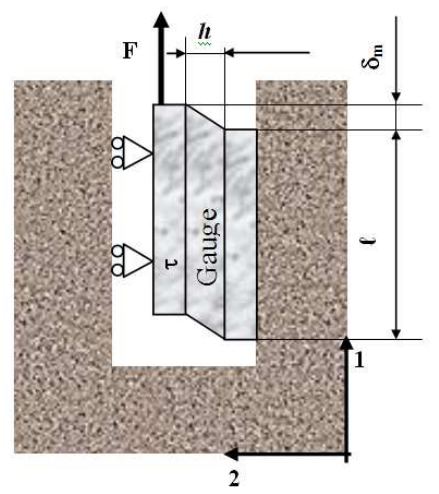

(b)

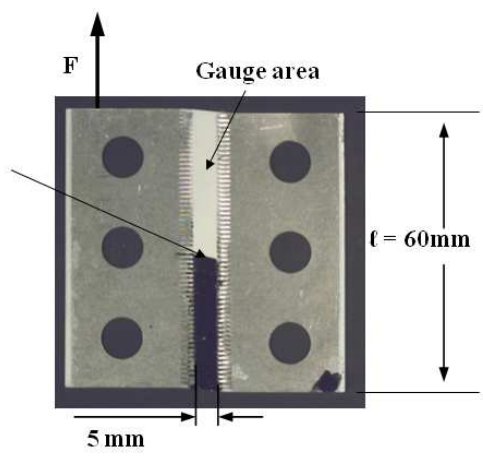

Figure 2. (a) Schematic representation of the simple shear device; $l$ and $h$ are, respectively, the current length and width of the gauge area and $\delta_{\mathrm{m}}$ is the relative displacement of the two lateral faces of the sample; this value is computed using a non contact measurement technique. (b) Deformed specimen with black line indicating the amount of shear strain.
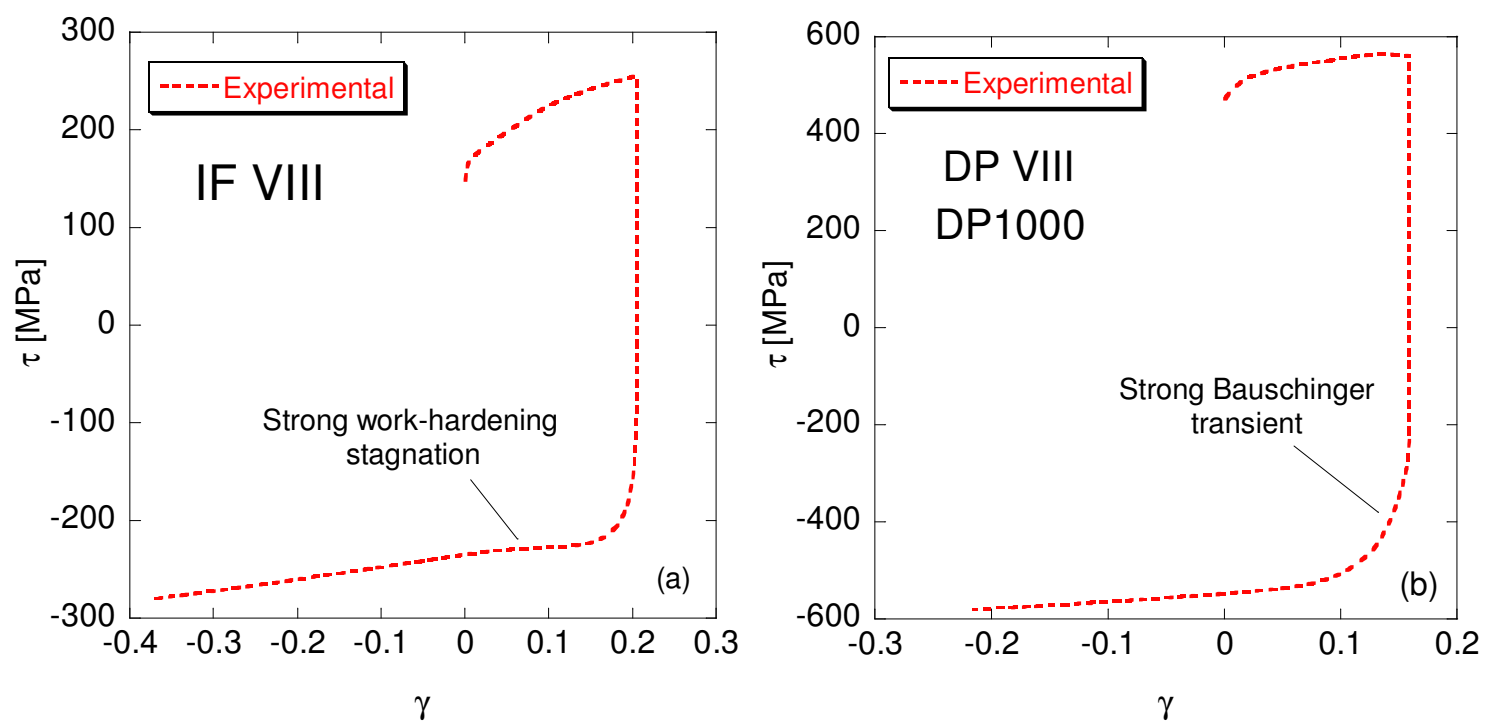

Figure 3. Experimental curves of a reversal simple shear test performed at $0^{\circ}$ to the RD for (a) IF VIII $\left(D_{F}=10.5 \mu \mathrm{m}\right)$ and (b) DP VIII (DP 1000).

For the orthogonal sequence, the experimental data for IF and DP steels was taken from 3DS report [3DS, 2001]. The simplest orthogonal test consists of the sequence of uniaxial tensile test followed by a simple shear test in the same direction. Further information is given by 
[Thuillier and Rauch, 1994], [Bouvier et al., 2006b]. An example of observed behavior is depicted in Figure 4.
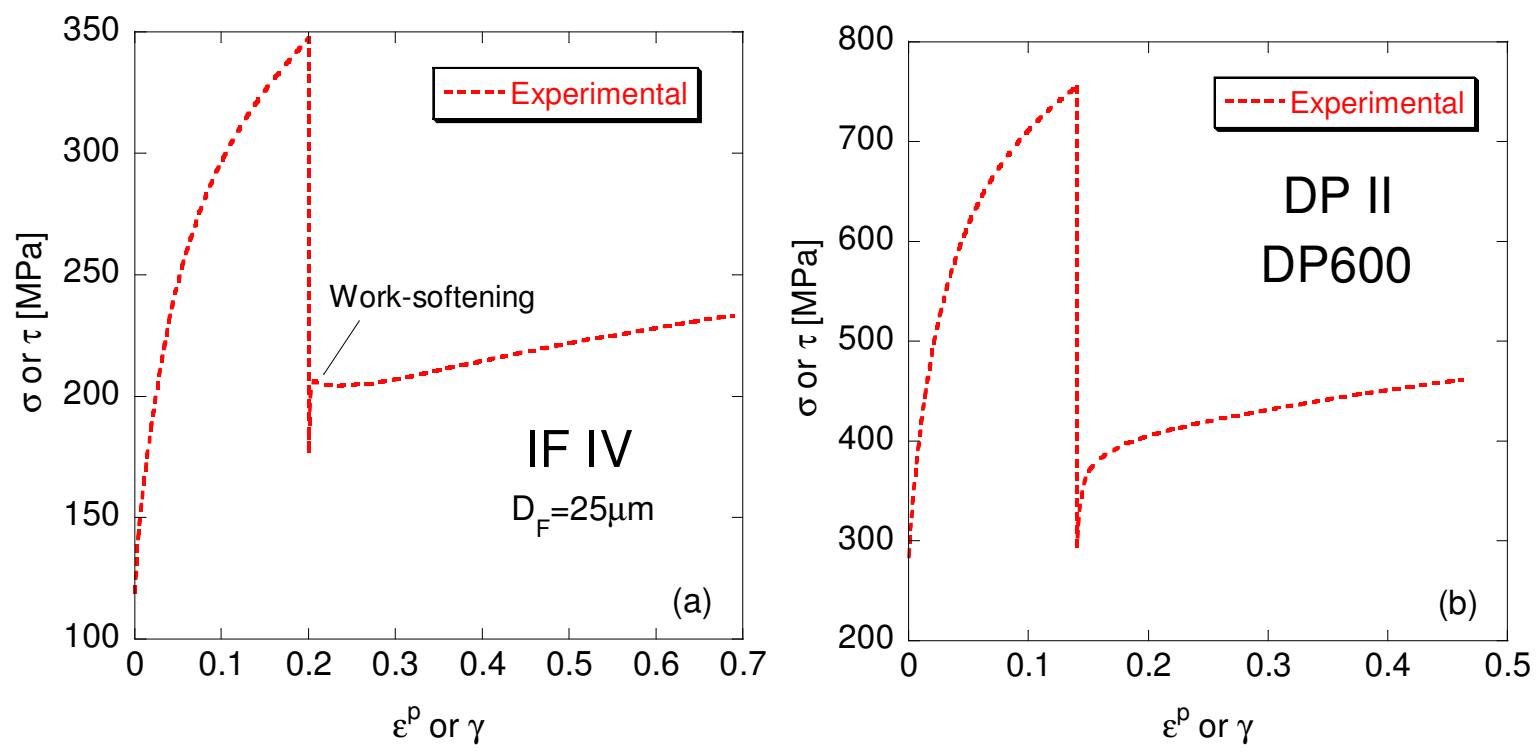

Figure 4. Experimental curves of orthogonal loading performed by a sequence of uniaxial tensile test along $0^{\circ}$ to the RD followed by simple shear test along $0^{\circ}$ to the RD for (a) IF IV $\left(D_{F}=25 \mu \mathrm{m}\right)$ and (b) DP II (DP 600). Experimental data taken from 3DS report [2001].

All the experimental data used in the present study was pre-processed using home-made Matlab@ routines. Stress versus strain experimental curves for uniaxial tensile and shear tests were smoothed in order to filter various possible noises due to the data acquisition.

Optical micrographs for the IF steels and SEM observations for the DP steels of the present work (i.e. IF VI to IX and all DP steels except DP II) were performed. SEM observations were realized with a Cambridge Stereoscan 360 field-emission scanning electron microscope (FE-SEM) chamber. Such observations allowed measuring mean grain sizes and phase volume fractions. Grain sizes were measured using ImageTool software. The procedure consisted of circling approximately 50 grains (for ferrite and martensite) in 4 different images per steel (i.e. two different images from different regions at the surface of the samples and two different images from different regions through sample thickness). Mean grain sizes are calculated by converting the measured cross sectional area of a feature to the diameter of an equal area circle (which is termed as mean grain size). The chosen procedure to measure the grain sizes gives a log-normal distribution in which a large standard deviation was observed. The martensite volume fraction was calculated by circling martensite regions and dividing their respective area by the total area of one image.

SEM observations revealed that DP steel microstructure is composed by martensite islands distributed in a ferrite matrix. It was found that ferrite mean grain size of the studied IF steels (IF VI to IX) vary in the $8-22 \mu \mathrm{m}$ value range. The ferrite and martensite mean grain sizes of the studied DP steels (all DP steels except DP II) vary in the $1.5-10 \mu \mathrm{m}$ value range. Martensite volume fraction is always under $25 \%$. The obtained values for grain sizes and martensite volume fractions are summarized in 
Table 4 and Table 5 for IF and DP steels, respectively.

\section{Dislocation-based constitutive modeling}

The model is developed in the general framework of cold deformation of metals and the viscous effects on the work-hardening behavior are neglected. At moderately large strains, because the main contribution to the work-hardening is due to the microstructural evolution, only this contribution in connection with the initial crystallographic texture is considered. The texture evolution during work-hardening and its influence on the work-hardening are neglected. In the modeling, much attention is paid to precisely simulating the behavior of the transient Bauschinger effect, as well as the work-hardening stagnation and work-softening. After a brief recall of the classical setting of rate-independent anisotropic plasticity, the proposed hardening model is introduced and coupled in the present work to the classical orthotropic [Hill, 1948] criterion. The latter is modified in order to take into account the sensitivity to material mean grain size. Conventional notations as defined in [Haddadi et al., 2006] are used.

\subsection{Yield condition and flow rule}

The present constitutive model has been developed within the framework of the yield surface concept. Based on the [Hill, 1948] criterion, the yield function $f$ is given by the following equation:

$$
f=\bar{\sigma}-Y=\bar{\sigma}-\left(\mathrm{Y}_{0}+R\right) \leq 0,
$$

where $Y$ is the yield stress and $Y_{0}$ is related to solid-solution and grain-size strengthening. It is worth noting that the initial yield stress is given by $Y_{0}+R(0)$. Moreover, work-hardening induced by plastic flow is assumed to be described by a combination of kinematic hardening $\mathbf{X}$ and isotropic hardening $R . \bar{\sigma}$ is the equivalent effective stress and is defined by

$$
\bar{\sigma}=\sqrt{\mathbf{T}: \mathbf{H}: \mathbf{T}}
$$

where $\mathbf{T}=\boldsymbol{\sigma}^{D}-\mathbf{X}$ and $\boldsymbol{\sigma}^{D}$ is the Cauchy stress deviator. $\mathbf{H}$ is a fourth-order tensor characterizing the texture anisotropy and has the symmetry properties $\mathrm{H}_{i j k l}=\mathrm{H}_{j i k l}=\mathrm{H}_{k j j i}$ and $\mathrm{H}_{i i k l}=0$.

The plastic flow occurs under the conditions $f=0$ and $(\partial f / \partial \sigma): \dot{\sigma}>0$. Under the classical normality assumption, the plastic strain rate tensor writes

$$
\mathbf{D}^{\mathrm{p}}=\frac{\partial f}{\partial \sigma} \dot{\lambda}=\frac{\mathbf{H}: \mathbf{T}}{\bar{\sigma}} \dot{\lambda},
$$

where $\dot{\lambda}$ is the plastic multiplier and is equal to the equivalent plastic strain rate $\dot{\bar{\varepsilon}}$.

\subsection{Yield criterion}

For practical applications, the quadratic [Hill, 1948] criterion is still the most attractive candidate due to its simplicity. In the present study, grain-size dependency of the Hill' 48 criterion parameters is proposed. The Voigt notation is used to exploit the symmetry 
properties of the forth-order tensor $\mathbf{H}$ in order to transform it to a second-order tensor defined by

$$
\mathbf{H}=\left[\begin{array}{cccccc}
G+H & -H & -G & 0 & 0 & 0 \\
-H & F+H & -F & 0 & 0 & 0 \\
-G & -F & F+G & 0 & 0 & 0 \\
0 & 0 & 0 & 2 L & 0 & 0 \\
0 & 0 & 0 & 0 & 2 M & 0 \\
0 & 0 & 0 & 0 & 0 & 2 N
\end{array}\right],
$$

where the components $F, G, H, L, M, N$ remain constant during the deformation if the texture evolution is neglected and are given by

$$
\left\{\begin{array}{l}
F=\frac{H}{r_{90^{\circ}}} \\
G=\frac{1}{1+r_{0^{\circ}}} \\
H=r_{0^{\circ}} G \\
N=\frac{1}{2} \frac{\left(r_{0^{\circ}}+r_{90^{\circ}}\right)\left(2 r_{45^{\circ}}+1\right)}{r_{90^{\circ}}\left(r_{0^{\circ}}+1\right)}
\end{array},\right.
$$

$r_{0^{\circ}}, r_{45^{\circ}}$ and $r_{90^{\circ}}$ are the anisotropy coefficients at $0^{\circ}, 45^{\circ}$ and $90^{\circ}$ from the rolling direction (RD), respectively. $r$-values are microstructure dependent and a large ferrite grain size yields high anisotropy coefficient values as given by the following equation [Karlyn et al., 1969], [Renavikar, 2003], [Xu et al., 2006]:

$$
r_{\alpha}=A_{\alpha} \log \left(D_{F}\right)+B_{\alpha},
$$

where $A_{\alpha}$ and $B_{\alpha}$ are constants and $D_{F}$ is the ferrite mean grain size (Table 6). Subscript $\alpha$ stands for the angle between the tensile specimen axis and the rolling direction of the sheet. The obtained results for $0^{\circ}$ and $90^{\circ}$ directions are better than for the $45^{\circ}$ direction (Figure 5). Indeed, the linear correlation coefficient in terms of data adjusting is found to be equal to $\mathrm{R}=$ 0.99 and $\mathrm{R}=0.98$, for $0^{\circ}$ and $90^{\circ}$ respectively, and $\mathrm{R}=0.79$ for $45^{\circ}$ direction (as indicated on Figure 5). This result could be related to the important strain-sensitivity of $r_{45^{\circ}}$ [Choi et al., 2006]. The corresponding slope for planar anisotropy is about 2.62, which is in reasonable agreement with literature data [Karlyn et al., 1969], [Xu et al., 2006]. 

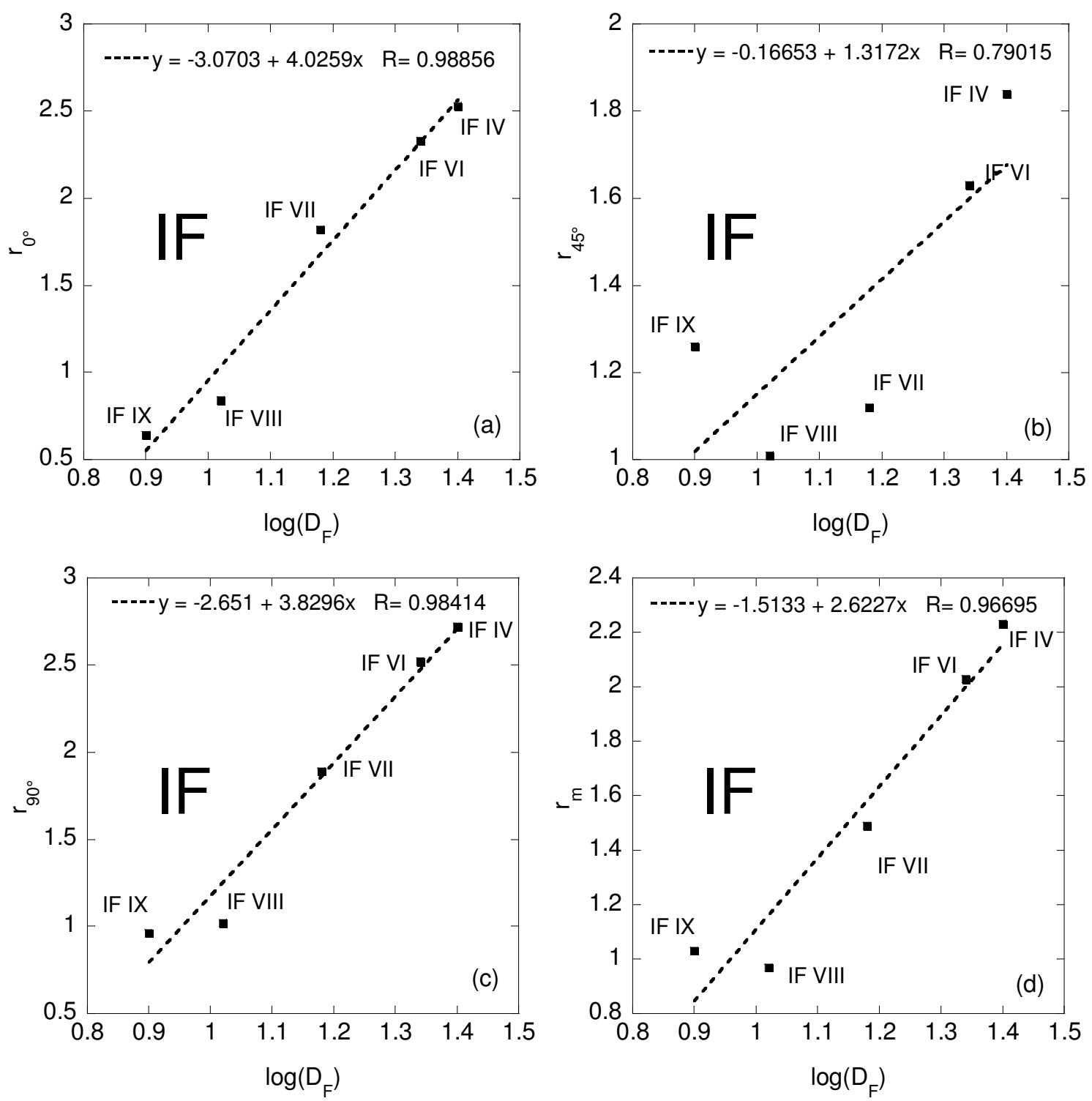

Figure 5. Relationship between the ferrite grain size and the anisotropy parameters at (a) $0^{\circ}$, (b) $45^{\circ}$, (c) $90^{\circ}$ as well as (d) the planar anisotropy $r_{m}=\frac{r_{0^{\circ}}+2 r_{45^{\circ}}+r_{90^{\circ}}}{4}$ for IF steels. $\mathrm{R}$ is the linear correlation coefficient.

Table 6. Linear law coefficients for the relationship between the anisotropy parameters and the grain size.

\begin{tabular}{ccc}
\hline & $A_{\alpha}$ & $B_{\alpha}$ \\
\hline$\alpha=0^{\circ}$ & 4.03 & -3.07 \\
$\alpha=45^{\circ}$ & 1.32 & -0.17 \\
$\alpha=90^{\circ}$ & 3.83 & -2.65 \\
\hline
\end{tabular}


For the present DP steels, the linear law for anisotropy parameters with respect to the ferrite average grain size is also attempted. Nonetheless, it is observed that $r$-values are rather close to 1, which indicates that DP steels are almost isotropic. Thus, in this study, DP steels will be characterized by the von Mises isotropic yield criterion.

\subsection{Description of the internal state variables}

A phenomenological model that incorporates details of the microstructure evolution at the grain-size scale was developed. The model consists of a combination of isotropic and kinematic contributions and modeling is based on the fact that the strengthening effect of mobile dislocation boundaries (depending on boundary spacing) acts in the same way as stationary grain boundaries (GBs). The key feature of modeling intragranular microstructure evolution consists in considering that cell block spatial dimensions composed of cell block boundaries (GNBs) and cell boundaries (IDBs) continuously refine with stress and strain [Winther and Jensen, 1997]. Hence, the total flow stress can be determined by the sum of IDBs and GNBs strengthening contributions. IDBs are assumed to be randomly oriented cell boundaries, which arise from the mutual trapping of dislocations into low energy configurations (i.e. dislocations trapped between GNBs and polarity dislocations dissolved from DWs). These boundaries are penetrable to slip and give rise to isotropic hardening. Thus, the IDBs evolution contribution is described by the Rauch and co-authors isotropic hardening model [Rauch et al., 2007], [Rauch et al., 2011], which is able to describe workhardening stagnation and work-softening. GNBs/IDBs incompatibility (dislocations glide easily in IDBs but hardly in GNBs) induces back-stresses and gives kinematic hardening at the macroscopic scale [Mughrabi et al., 1986], [Wilson and Bate, 1996]. Phenomena such as the Bauschinger effect are described through the back-stress. A grain-size dependent backstress description was proposed by Sinclair et al. [2006]. A tensorial expression for the backstress was further proposed by Aouafi et al. [2007] in order to describe the plastic anisotropy.

\subsubsection{Isotropic work-hardening}

The Taylor formulation [Taylor, 1934] offers an adequate framework to describe plasticity related to the dislocation density $\rho$. The yield stress can be written as

$$
Y=\sum_{I} V_{I}\left(Y_{0 I}+R_{I}\right)=\sum_{I} V_{I}\left(Y_{0 I}+M \alpha G b \sqrt{\rho_{I}}\right)
$$

and

$$
R_{I}(0)=M \alpha G b \sqrt{\left(\rho^{0}\right)_{I}} .
$$

$I$ represents the different phases in the material (e.g. ferrite, martensite...) with $V_{I}$ their respective volume fraction. In this work, for DP steels, $I=F, M$; where $F$ stands for ferrite/ferrite interface and $M$ for ferrite/martensite interface. $G$ stands for the shear modulus and $b$ for the magnitude of the Burgers vector and their values are set to be $G=80 \mathrm{GPa}$ and $b=2.5 \times 10^{-10} \mathrm{~m}$, respectively. $M$ is the Taylor factor and is assumed to be equal to the average Taylor factor $\langle M\rangle$. In this work, we assume that the studied steels have perfect $\gamma$ - 
fiber. Hence, we assume that $M$ is equal to 3.14 [Murakami, 2008]. $\alpha$ represents the dislocation interaction and is taken equal to 0.4 [Feaugas, 1999]. For IF steels, the initial dislocation density is set to be equal to $\rho^{0}=10^{12} \mathrm{~m}^{-2}$. In DP steels, the dislocation density in the ferrite/martensite interface is higher than within the ferrite grain, their initial dislocation density is equal to $\rho^{0}=10^{13} \mathrm{~m}^{-2}$ [Gardey et al., 2005ab]. $Y_{0 n}$ is estimated through grain size and chemical composition using the following combination of Hall-Petch and Pickering [1992] relations:

$$
Y_{0 n}=\frac{\left(k_{H P}\right)_{n}}{\sqrt{D_{F}}}+42[\mathrm{Mn}]^{0.54}+750[\mathrm{P}]+60[\mathrm{Si}]+80[\mathrm{Cu}]+80[\mathrm{Ti}]+2400[\mathrm{Nb}]+5000[\mathrm{~N}],
$$

where [·] designates the weight percent concentration of the solutes. $k_{H P}$ is the Hall-Petch coefficient ( $k_{H P} \approx 15-18 \mathrm{MPa} \sqrt{\mathrm{mm}}$ for low-carbon steels [Gladman, 1997]). In the present work, we opted for an intermediate value for IF steels: $k_{H P}=16.5 \mathrm{MPa} \sqrt{\mathrm{mm}}$. In DP steels, $k_{H P}=20 \mathrm{MPa} \sqrt{\mathrm{mm}}$ [Morrison, 1966].

The dislocation density evolution with strain is based on the equations proposed in the [Rauch et al. 2011] model, which consists in describing the intragranular evolution of dislocation structure by splitting the total dislocation density in three components:

$\rho_{I}=\rho_{F / I}+\rho_{R / I}+\rho_{L / I}$, where $\rho_{F / I}, \rho_{R / I}, \rho_{L / I}$ are associated with forward, reverse and latent substructures, respectively. It is important to stand out that the total dislocation density $(\rho)$ is the only one that can be experimentally measured and consequently has a physical meaning. The other terms $\left(\rho_{F / I}, \rho_{R / I}, \rho_{L / I}\right)$ are phenomenological distributions of this total dislocation density. These terms are taken over from their respective hardening counterparts.

Initially, and throughout monotonic loading, $\rho_{R / I}=\rho_{L / I}=0$. When a reverse strain-path change occurs, a fraction $p$ of the total dislocation density cumulated during pre-strain is associated with dislocations that move along the opposite slip direction of previously activated slip systems. This "reverse" type dislocation density corresponds to $\rho_{R / I}$ and the remaining part of $\rho_{I_{\text {pre }}}$ accounts as "forward": $\rho_{R / I}^{0}=p \rho_{I_{\text {pre }}} ; \rho_{F / I}^{0}=\rho_{I_{\text {pre }}}-\rho_{R / I}^{0}$. After an orthogonal strain-path change (e.g., tensile test followed by shear test in the same direction), the entire dislocation density becomes of "latent" type: $\rho_{L / I}^{0}=\rho_{I_{p r e}} ; \rho_{F / I}^{0}=0$. Here, "pre" designates values at the end of the pre-strain stage and " 0 " designates values at the beginning of the subsequent stage. These definitions are sufficient for the simulation of the one-dimensional two-step strain paths typical of mechanical tests used for parameter identification. Along a general strain-path change, the total dislocation density can be decomposed into its three components according to the following more general rule:

$$
\begin{aligned}
& \rho_{R / I}^{0}=p \theta^{2} \rho_{I_{\text {pre }}} \\
& \rho_{L / I}^{0}=\left(1-\theta^{2}\right) \rho_{I_{\text {pre }}}, \\
& \rho_{F / I}^{0}=\rho_{I_{\text {pre }}}-\rho_{R / I}^{0}-\rho_{L / I}^{0}
\end{aligned}
$$

where $\theta$ is the classical Schmitt factor

$$
\theta=\mathbf{N}_{p r e}: \mathbf{N},
$$


and $\mathbf{N}=\mathbf{D}^{\mathrm{p}} /\left\|\mathbf{D}^{\mathrm{p}}\right\|$ is the direction of the plastic strain rate tensor.

The evolution laws for the "forward", "reverse" and "latent" components of the isotropic hardening internal variable are given by

$$
\begin{aligned}
& \dot{\rho}_{F / I}=H_{\rho_{F / I}} \dot{\bar{\varepsilon}}=M\left(k_{1} \sqrt{\rho_{F / I}}-k_{2} \rho_{F / I}+\frac{k_{3 I}}{b D_{I}}\right) \dot{\bar{\varepsilon}} \\
& \dot{\rho}_{R / I}=H_{\rho_{R / I}} \dot{\bar{\varepsilon}}=-M\left(k_{1} \sqrt{\rho_{F / I}}+\frac{k_{3 I}}{b D_{I}}\right) \frac{\rho_{R / I}}{\rho_{I_{p r e}}} \dot{\bar{\varepsilon}}, \\
& \dot{\rho}_{L / I}=H_{\rho_{L / I}} \dot{\bar{\varepsilon}}=-M k_{2} \rho_{L / I} \dot{\bar{\varepsilon}}
\end{aligned}
$$

where $k_{1}, k_{2}$ and $k_{3 I}$ are related to the athermal work-hardening limit and the dynamic recovery, respectively. $k_{3 F}=k_{3}$, the value taken for the IF steels and $k_{3 M}=8 M V_{M}, M$ is the Taylor factor and $V_{M}$ is the volume fraction of the martensite phase. $k_{3}$ is a geometric factor related to the proportion of dislocations arriving at the boundaries. $k_{1}, k_{2}$ and $k_{3}$ are fitting parameters and are set to be constant. The description of the work-hardening stagnation and softening is correlated to the $k_{1} / k_{2}$ combination.

\subsubsection{Kinematic work-hardening}

The kinematic contribution for a monotonic loading is given by [Sinclair et al., 2006]:

$$
X=M \frac{G b}{D_{F}} n_{0}\left(1-\mathrm{e}^{-\frac{\lambda}{b n_{0}} \bar{\varepsilon}}\right),
$$

where $M G b n_{0} / D_{F}$ stands for the saturation value of the kinematic contribution and $\lambda / b n_{0}$ is the saturation rate of the kinematic contribution. $\lambda$ is the mean DWs spacing, which decreases with strain. Nonetheless, for the sake of simplicity, because this parameter quickly reaches its final value (after approximately 3\%-4\% plastic strain [Uenishi, 2003]), we assume it as a constant. $n_{0}$ is the "maximum number of dislocations" that can be stored at a boundary on a given slip band (or slip line). $\lambda$ and $n_{0}$ are fitting parameters.

Because Eq. (14) is a phenomenological description in which polycrystals are characterized with what is observed in single crystals, $n_{0}$ should rather be considered as a parameter that introduces the concept of internal stress saturation. By differentiating Eq. (14) we obtain:

$$
\dot{X}=\frac{\lambda}{b n_{0}}\left(M \frac{G b}{D_{F}} n_{0}-X\right) \dot{\bar{\varepsilon}},
$$

During uniaxial deformation, the kinematic hardening introduced in Eq. (15) coincides with the phenomenological non-linear evolution law proposed by Armstrong and Frederick [1966]. Hence, its tensorial expression is given by (see, e.g. Aouafi et al. [2007]):

$$
\dot{\mathbf{X}}=C_{X}\left(X_{s a t} \mathbf{N}-\mathbf{X}\right) \dot{\bar{\varepsilon}},
$$

where $X_{s a t}=M \frac{G b}{D_{F}} n_{0}$ and $C_{X}=\frac{\lambda}{b n_{0}}$. 
It is worth noting that contrarily to isotropic hardening, the kinematic hardening expression remains unchanged for DP steels.

\section{Numerical procedure}

\subsection{Model identification}

The phenomenological model that incorporates details of the microstructure evolution at the grain-size scale presented previously was implemented in MATLAB. The identification of the set of fixed physically-based constant parameters (i.e. $k_{1}, k_{2}, k_{3}, \lambda$ and $n_{0}$ ) was carried out using the fminsearch routine, which attempts to find a constrained minimum of a scalar function of several variables starting from an initial parameter set. The set of experimental tests used for the material parameter identification is composed of six mechanical tests: a uniaxial tensile test, a simple shear test, a reverse simple shear (i.e. Bauschinger) loading at three amounts of shear pre-strain $(10 \%, 20 \%$ and 30\%) and an orthogonal loading $(10 \%$ tensile pre-strain followed by a simple shear test). It is noteworthy that identification should be done on coarse grain size materials because the effect on the grain boundary region is negligible [Pipard et al., 2009]. The obtained results for IF and DP steels are shown in Figure 6 . The evolution of dislocation densities for IF IV and DP II during reverse and orthogonal loading is shown in Figure 7 and Figure 8, respectively. Note the stagnation and the decrease of the total dislocation density during reverse and orthogonal loadings for IF IV. The fitting parameter values for IF and DP steels are presented in Table 7 and Table 8, respectively. For industrial applications, the use of orthogonal tests increases the identification time. Hence, the previous identification procedure was done again for IF IV using only two mechanical tests: uniaxial tensile test and reverse loading with $30 \%$ of shear pre-strain. The obtained fitted parameter values are reasonably close to those of the complete identification procedure, which means that a reduced experimental basis can be used without important loss in accuracy. The corresponding material parameter values are reported in Table 9. 

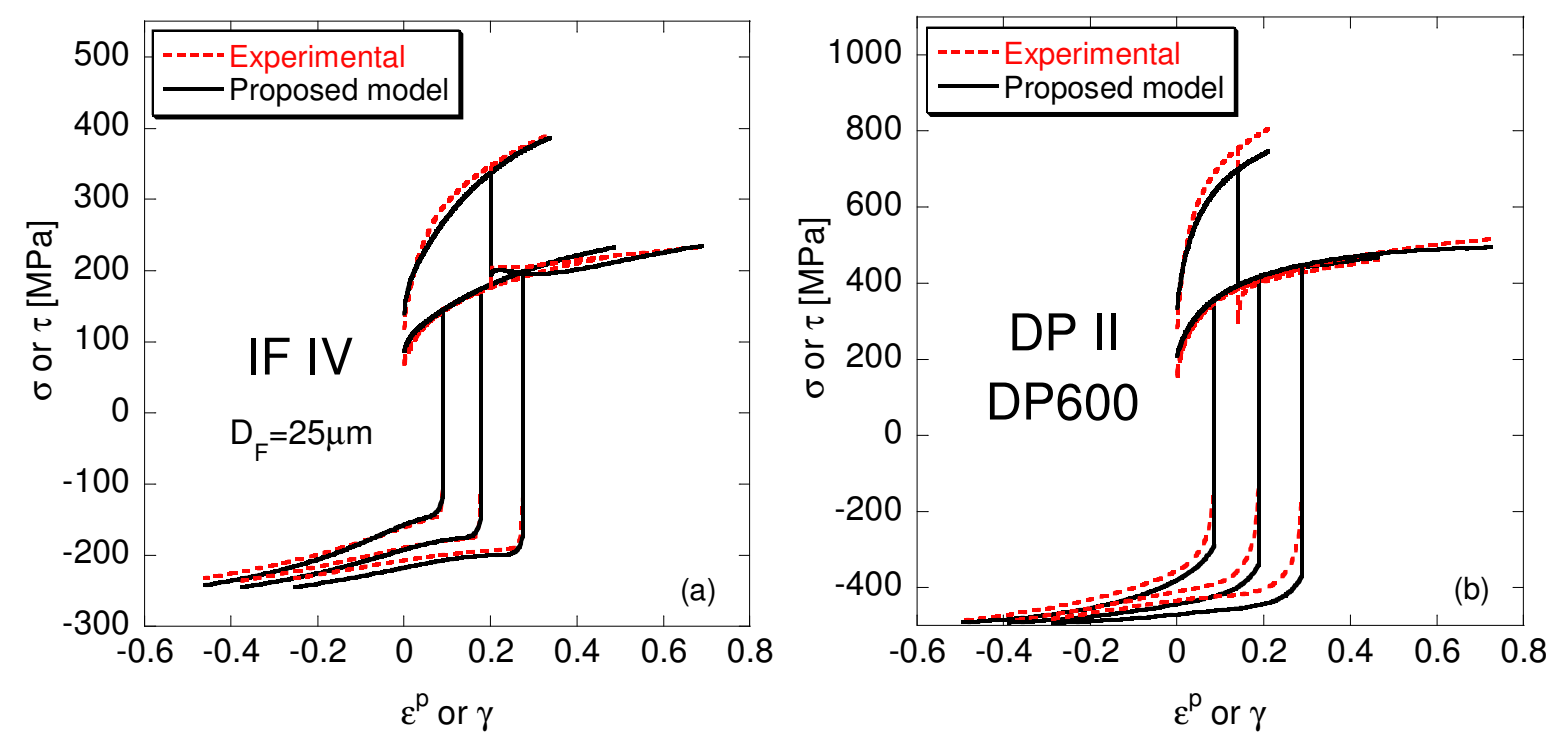

Figure 6. Results of the Advanced Microstructural model identification procedure for (a) IF IV steel and (b) DP II steel using 6 mechanical tests I.
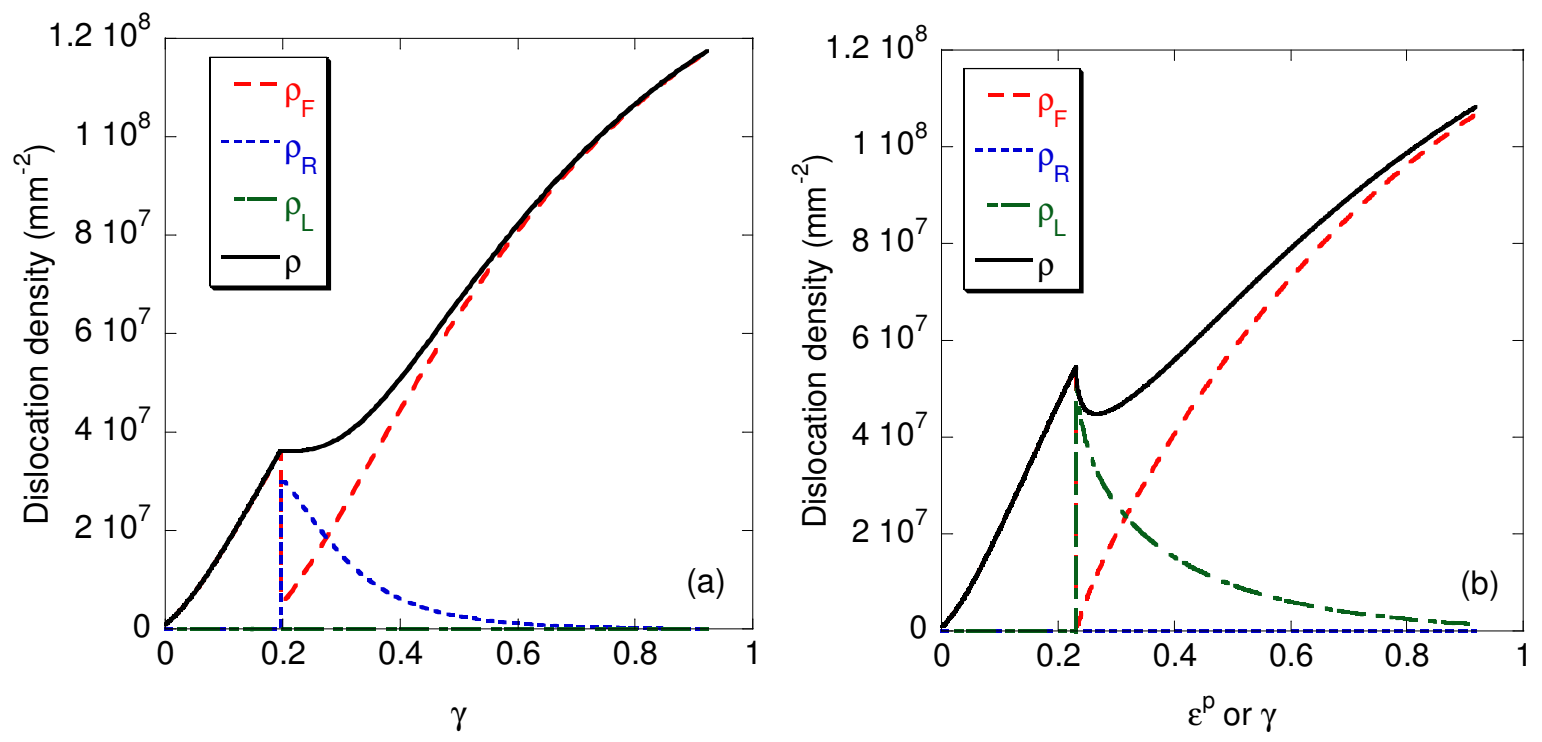

Figure 7. IF steel (IF IV) dislocation density evolution related to (a) reverse and (b) orthogonal loading. Note the stagnation in case (a) and the softening in case (b) of the total dislocation density. 

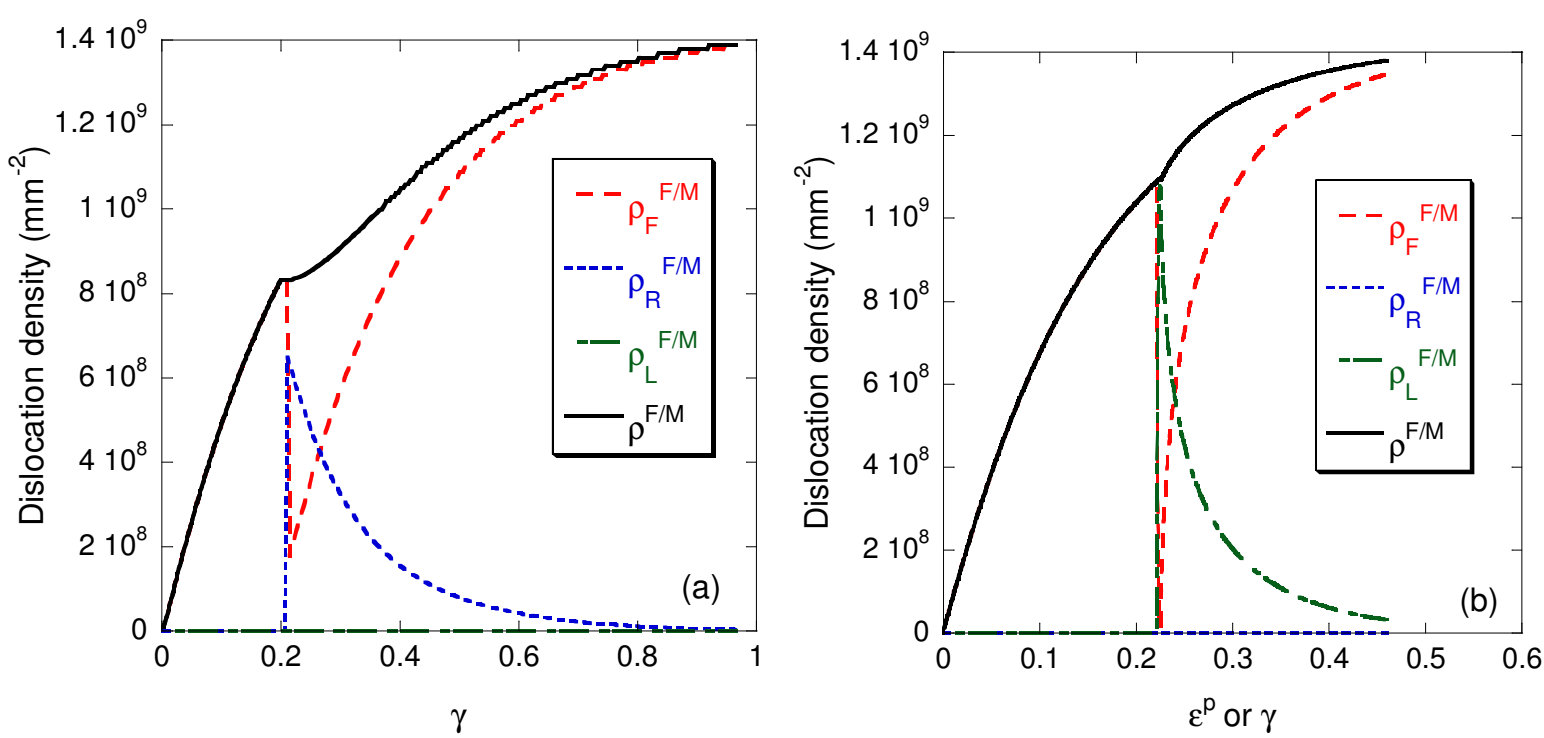

Figure 8. DP steel (DP II) ferrite/martensite boundary dislocation density evolution related to (a) reverse and (b) orthogonal loading. Note that stagnation and no softening of the total ferrite/martensite boundary dislocation density occur in case (a) and (b), respectively.

Table 7. Advanced Microstructural model fitted parameters for IF steel IV with six mechanical tests.

\begin{tabular}{cccccc}
\hline$k_{1}\left(\mathrm{~nm}^{-1}\right)$ & $k_{2}$ & $k_{3}$ & $\lambda(\mathrm{nm})$ & $n_{0}$ & $p$ \\
\hline 0.031 & 2.7 & 0.1 & 415 & 10.3 & 0.83 \\
\hline
\end{tabular}

Table 8. Advanced Microstructural model fitted parameters for DP steel II with six mechanical tests.

\begin{tabular}{cccccc}
\hline$k_{1}\left(\mathrm{~nm}^{-1}\right)$ & $k_{2}$ & $k_{3}$ & $\lambda(\mathrm{nm})$ & $n_{0}$ & $p$ \\
\hline 0.033 & 3.1 & 0.1 & 61 & 6.2 & 0.81 \\
\hline
\end{tabular}

Table 9. Advanced Microstructural model fitted parameters for IF steel IV with two mechanical tests (tensile and reverse loadings).

\begin{tabular}{cccccc}
\hline$k_{1}\left(\mathrm{~nm}^{-1}\right)$ & $k_{2}$ & $k_{3}$ & $\lambda(\mathrm{nm})$ & $n_{0}$ & $p$ \\
\hline 0.035 & 2.6 & 0.1 & 360 & 11.1 & 0.86 \\
\hline
\end{tabular}

\subsection{Grain size effect simulation}

Many recent works have been focusing on grain size effects on the overall plastic behaviour through more "homogenized" material models [Chia et al., 2005], [Sinclair et al., 2006], [Pipard et al., 2009]. These "homogenized" models have proven to quantitatively estimate the grain size effect through relatively easy equations (e.g. Kocks-Mecking-Estrin theory).

Because identification procedures are known to be time-consuming, car manufacturers try to avoid them whenever possible. Hence, the aim of this section is to assess an approach that allows avoiding identification procedures. This approach consists in accurately estimating 
steel behaviour by only changing few microstructure data, such as ferrite $D_{F}$ and martensite $D_{M}$ mean grain sizes, martensite volume fraction $V_{M}$ and the chemical composition in Eqs. (10), (13) and (14). Ferrite and martensite mean grain sizes and martensite volume fraction affect the yield stress and work-hardening while the chemical composition only affects the initial yield stress. The proposed predictive approach is obtained through a set of fixed physically-based constant parameters $\left(k_{1}, k_{2}, k_{3}, \lambda, n_{0}\right)$ that are identified only once. This means that the same material parameters (those identified only once for IF and DP steels) are subsequently used to simulate the response of other IF and DP steels. The simulated curves are able to quantitatively predict the effect of grain size on work-hardening for IF and DP steels as depicted in Figure 9 and Figure 10 to Figure 13, respectively.
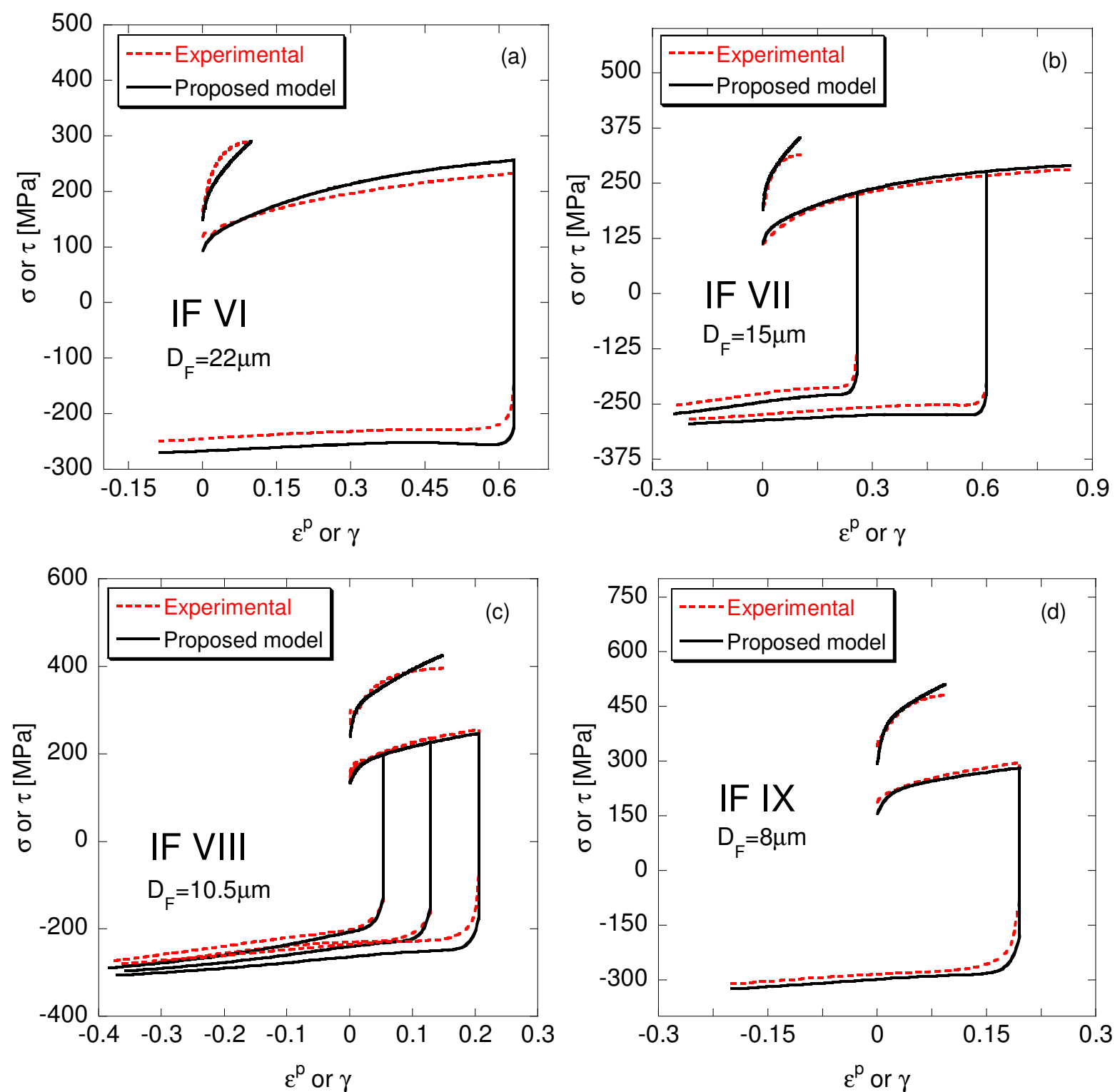

Figure 9. Estimated (obtained without any identification procedure) work-hardening behavior of IF VI to IX (grain size varies from $22 \mu \mathrm{m}$ to $8 \mu \mathrm{m}$ ) through a set of fixed physically-based constant parameters $\left(k_{1}, k_{2}, k_{3}, \lambda, n_{0}\right)$ for IF steels. Only the mean grain size and chemical composition are modified. 


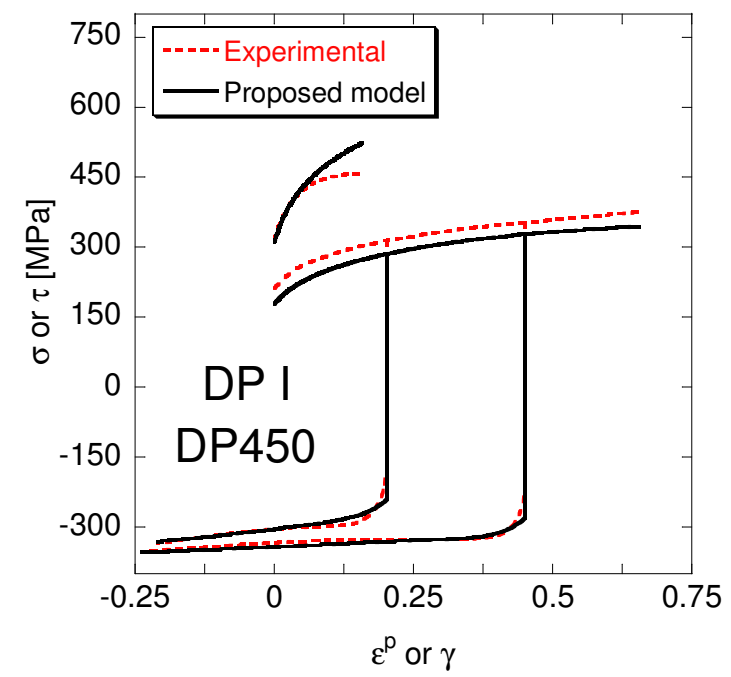

Figure 10. Estimated (obtained without any identification procedure) work-hardening behavior of DP I (DP 450) through a set of fixed physically-based constant parameters $\left(k_{1}\right.$, $k_{2}, k_{3}, \lambda, n_{0}$ ) for DP steels. Only the mean grain sizes (ferrite, martensite), martensite volume fraction and chemical composition are modified.
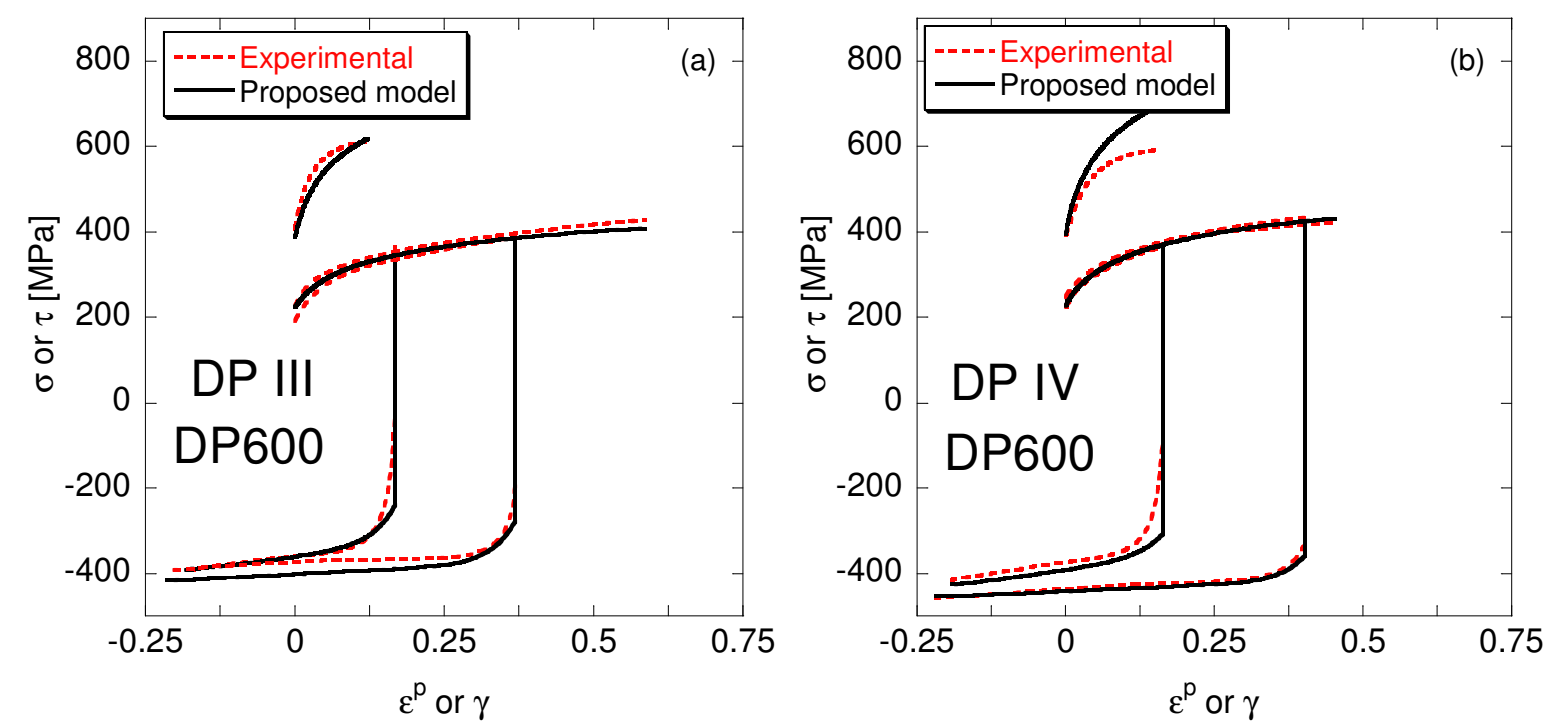

Figure 11. Estimated (obtained without any identification procedure) work-hardening behavior of two different DP 600 steels ((a) DP III and (b) DP IV) through a set of fixed physically-based constant parameters $\left(k_{1}, k_{2}, k_{3}, \lambda, n_{0}\right)$ for DP steels. Only the mean grain sizes (ferrite, martensite), martensite volume fraction and chemical composition are modified. 

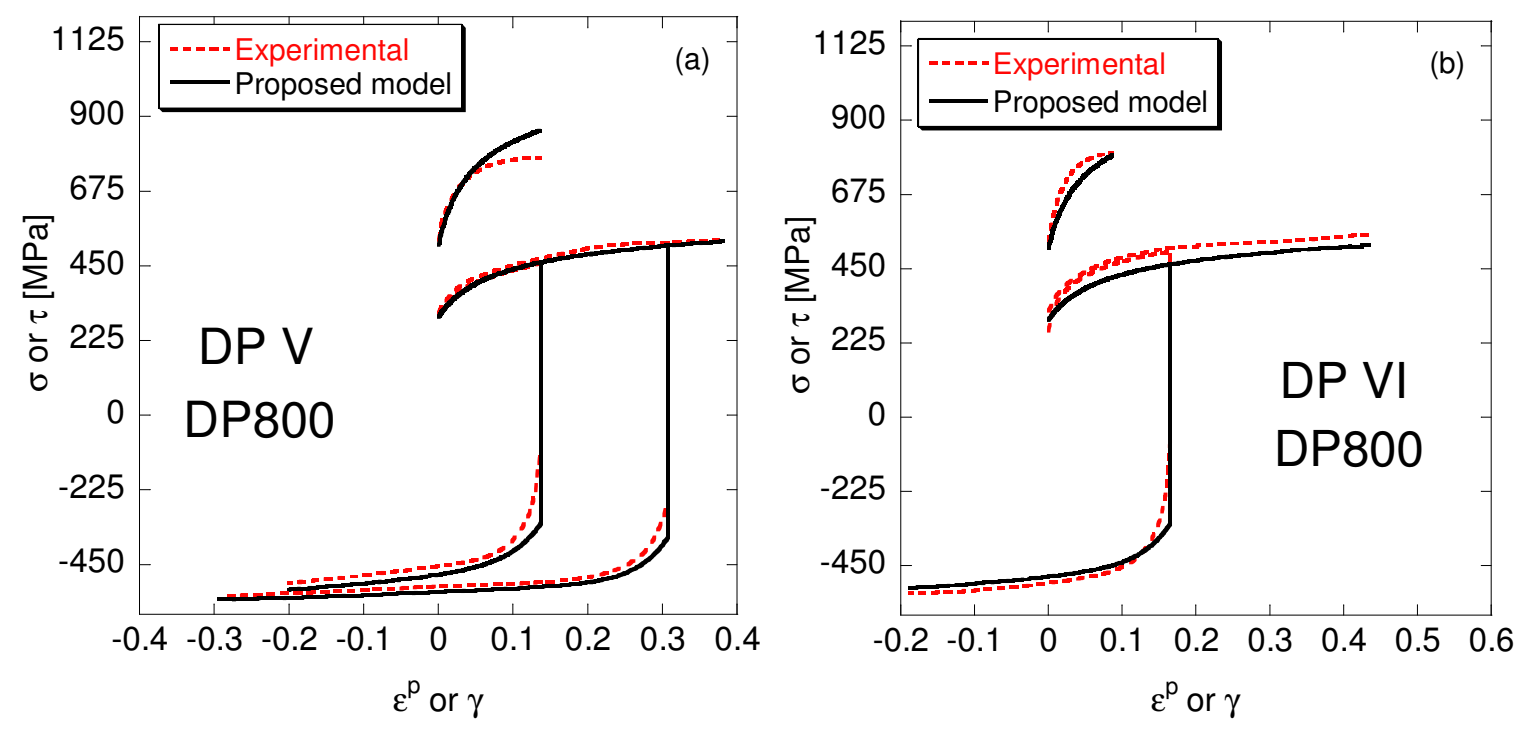

Figure 12. Estimated (obtained without any identification procedure) work-hardening behavior of two different DP 800 steels ((a) DP V and (b) DP VI) through a set of fixed physically-based constant parameters $\left(k_{1}, k_{2}, k_{3}, \lambda, n_{0}\right)$ for DP steels. Only the mean grain sizes (ferrite, martensite), martensite volume fraction and chemical composition are modified.
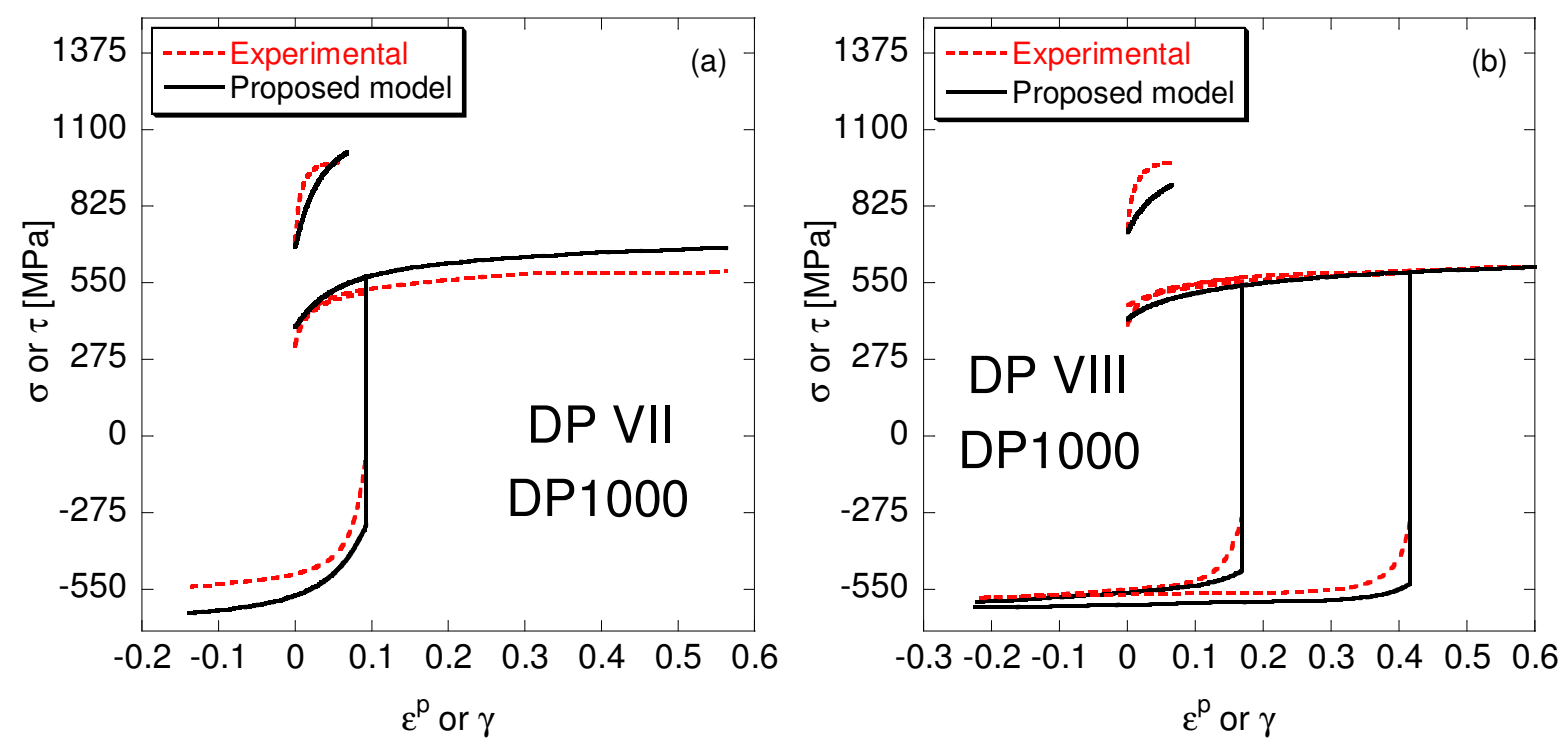

Figure 13. Estimated (obtained without any identification procedure) work-hardening behavior of two different DP 1000 steels ((a) DP VII and (b) DP VIII) through a set of fixed physically-based constant parameters $\left(k_{1}, k_{2}, k_{3}, \lambda, n_{0}\right)$ for DP steels. Only the mean grain sizes (ferrite, martensite), martensite volume fraction and chemical composition are modified. 


\section{Description of material parameters and sensitivity analysis}

\subsection{Sensitivity to the Taylor factor $M$}

It is well admitted that IF steels have a weak texture in the hot rolled state, which is dominated by $\alpha$-fiber and evolves in such steels during cold rolling to produce two typical fibers. One of these is the partial $\alpha$-fiber with $<011>/ /$ RD and the other is the complete $<111>/$ /ND $\gamma$-fiber, which appears to be predominant [Lücke and Hölscher, 1991], [Hirsch et $a l ., 1991]$. The grains of the $\gamma$-fiber have a high Taylor factor, whereas those of the $\alpha$-fiber have a low Taylor factor [Hutchinson, 1999]. Indeed, it was found that perfect $\alpha$-fiber and perfect $\gamma$-fiber have Taylor factors equal to 2.47 and 3.14, respectively [Murakami, 2008] and this affect the macroscopic behavior (Figure 14). In low carbon steels, rolling processes generate a fiber texture that leads to a practically constant Taylor factor over a wide strain range [Lopes et al., 2003]. Hence, the Taylor factor is taken as a constant and equals $M=$ 3.14 .
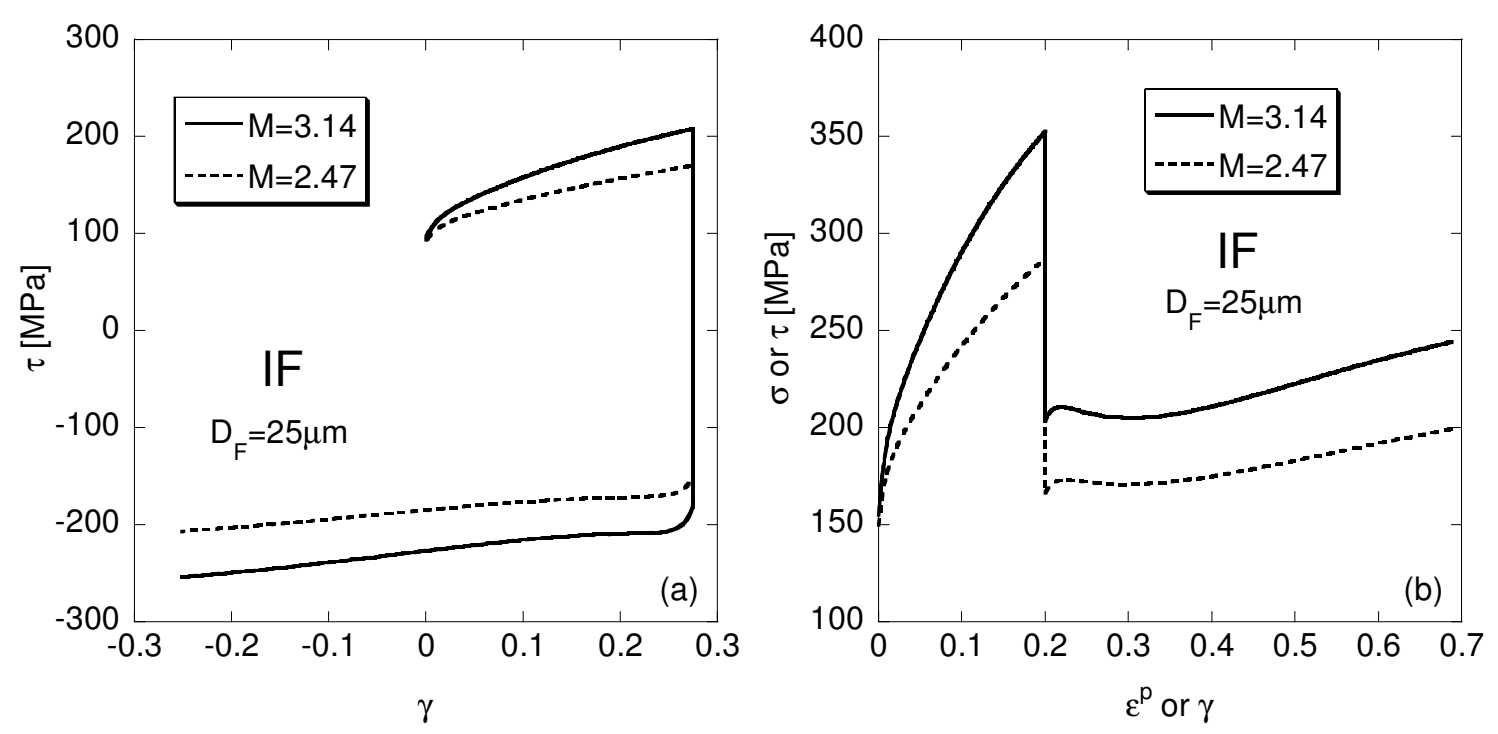

Figure 14. Estimated crystallographic texture effect on work-hardening for $\gamma$-fiber $(\mathrm{M}=$ 3.14) and $\alpha$-fiber ( $\mathrm{M}=2.47)$ IF steel with grain size $D_{F}=25 \mu \mathrm{m}$ for (a) reverse and (b) orthogonal loadings.

\subsection{Sensitivity to parameter $k_{1}$}

$k_{1}$ stands for the athermal hardening rate parameter, which results in hardening (see Eq. (13)). $k_{1}$ is significantly influenced by the microstructure [Fang and Dahl, 1995]. Increasing $k_{1}$ yields a higher work-hardening rate (Figure 15). Values of $k_{1}$ ranging from 0.02 to $0.08 \mathrm{~nm}^{-1}$ are found for low carbon steels in the literature [Bouquerel et al., 2006], [Bouaziz and Dirras, 2006], [Rauch et al., 2007], [Rauch et al., 2011]. Recently, the [Rauch et al., 2011] model 
was used to describe DP steel behavior by Barlat et al. [2011]. A $k_{1}$ value equal to $0.036 \mathrm{~nm}^{-1}$ was found. Hence, the $k_{1}$ values obtained by identification are in good agreement with those found in the literature. It is generally assumed that the work-hardening rate during stage II is related to athermal hardening (i.e., $k_{1}$ ) [Kocks and Mecking, 2003] and it is set to be constant. The characteristic DP steel behavior shows that the work-hardening rate at low strains (i.e. stage II) is higher than that of IF steels. This phenomenon is reflected in the present models by finding a larger $k_{1}$ value for DP steels.
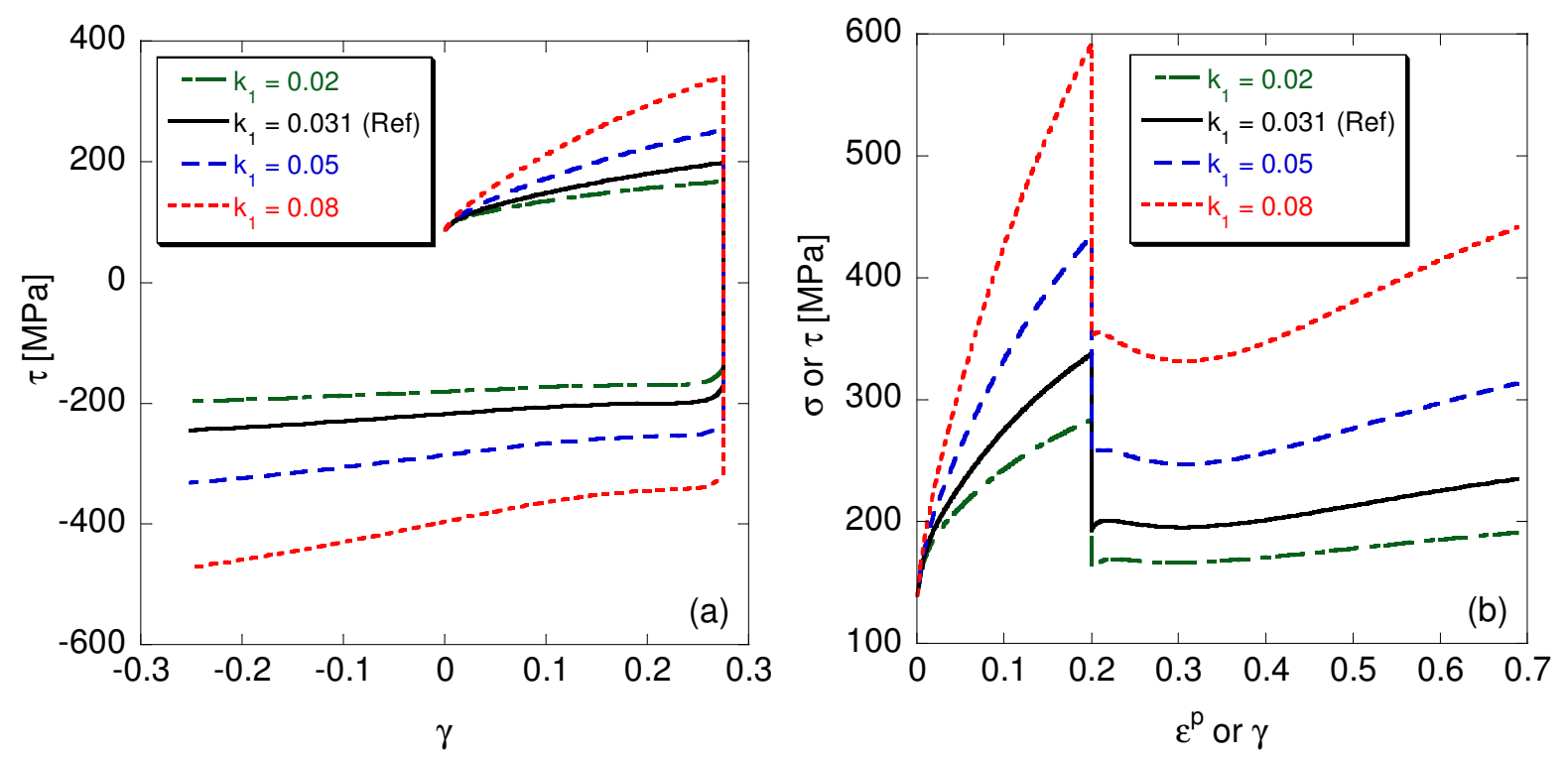

Figure 15. Estimated dislocation storage rate effect on work-hardening for IF steel with grain size $D_{F}=25 \mu \mathrm{m}$ for (a) reverse and (b) orthogonal loadings. $\mathrm{K}_{1}$ is given in $\mathrm{nm}^{-1}$.

Uenishi [2003] elaborated three materials with the same grain size but with different chemical compositions. Alloys were made by nominal addition of $1 \%$ by weight of Si (IF II) and $2 \%$ of $\mathrm{Si}$ and Mn (IF III) to a base material (IF I). Inspection of reverse loading curves for these steels reveals a strong Bauschinger effect followed by stagnation and then resumption of work-hardening. In IF I and IF II steels, the stagnation of the work-hardening is evident when the reversed deformation follows a sufficiently large forward pre-strain. Nevertheless, such stagnation is not clearly observed in the case of IF III steel, for which the work-hardening rate is also higher. Numerically, the present model is not able to capture the chemical composition effect on work-hardening (Figure 16). However, considering the physical meaning of the model parameters, it can be concluded that solid solution strengthening is directly related to $k_{1}$ parameter. Thus, a modification of $k_{1}$ induces a change in the $k_{1} / k_{2}$ ratio and consequently a change in the work-hardening stagnation and softening description, which is in accordance with Uenishi's experimental observations [Uenishi, 2003]. 

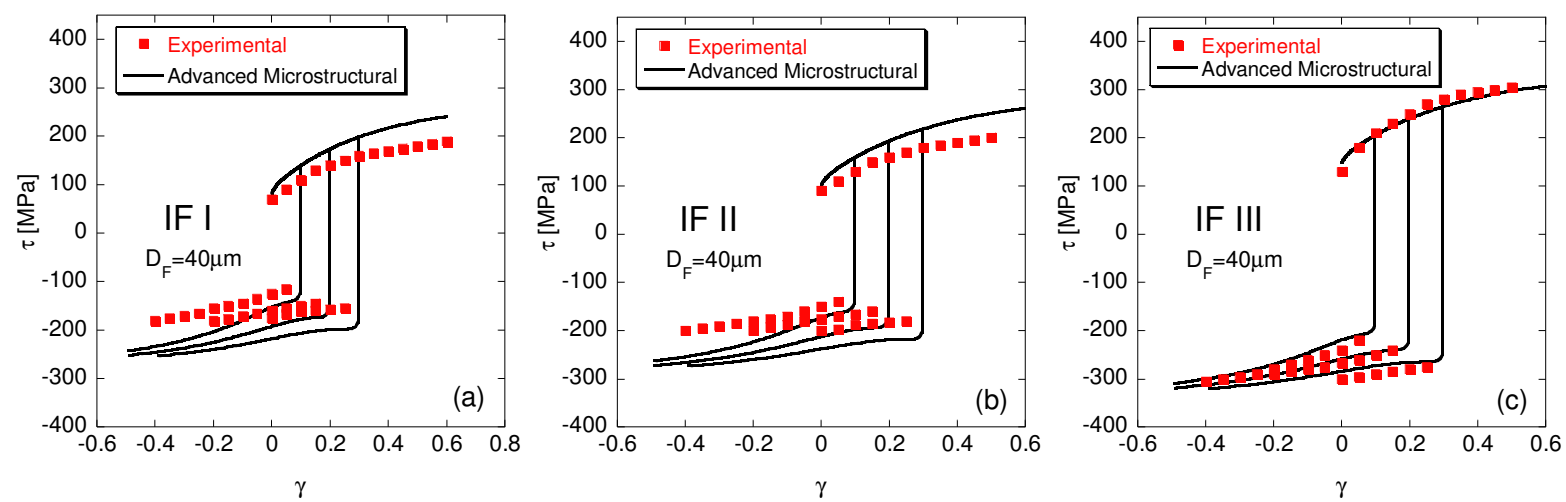

Figure 16. Solid solution strengthening effect on IF steels: (a) base material (IF I), (b) addition of $1 \% \mathrm{Si}$ to IF I (IF II) and (c) addition of $2 \% \mathrm{Si}$ and $2 \% \mathrm{Mn}$ to IF I (IF III). Experimental data was extracted from [Uenishi and Teodosiu, 2003].

\subsection{Sensitivity to parameter $k_{2}$}

$k_{2}$ stands for the dynamic recovery parameter, which results in softening (Figure 17). It is usually admitted to set this parameter as a constant [Kocks and Mecking, 2003]. $k_{2}$ may be considered as microstructure independent but it is temperature and strain-rate dependent [Fang and Dahl, 1995]. $k_{2}$ values equal to 2.7 (IF steels) and to 3.1 (DP steels) were obtained by identification and are in good agreement with the 2.8-22 value range found for IF steels [Fang and Dahl, 1995], [Bouaziz and Dirras, 2006], [Rauch et al., 2007], [Rauch et al., 2011] and DP steels [Barlat et al., 2011].
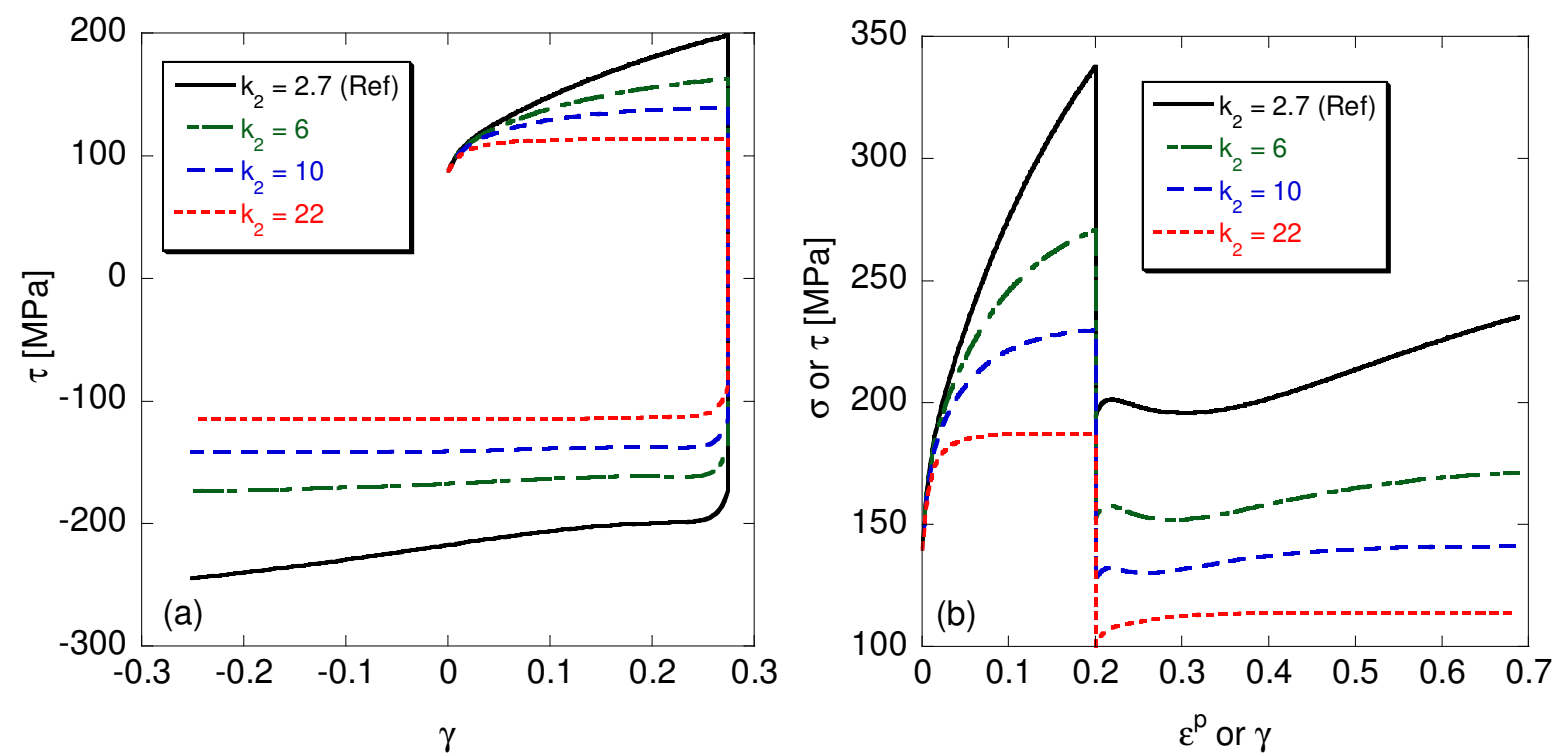

Figure 17. Estimated dynamic recovery effect on work-hardening for IF steel with grain size $D_{F}=25 \mu \mathrm{m}$ for (a) reverse and (b) orthogonal loadings. 


\subsection{Sensitivity to parameter $k_{3}$}

$k_{3}$ is a geometric factor related to the proportion of dislocations arriving at the boundaries. Higher $k_{3}$ values result in hardening (Figure 18). Grain boundary densities represent only a few per cent of the total dislocations and play a minor role in material strengthening [Mughrabi, 2006]. Hence, a low value for $k_{3}$ is expected. The identification procedure led to $k_{3}=0.1$, which is in agreement with the value found by Delincé et al. [2007].
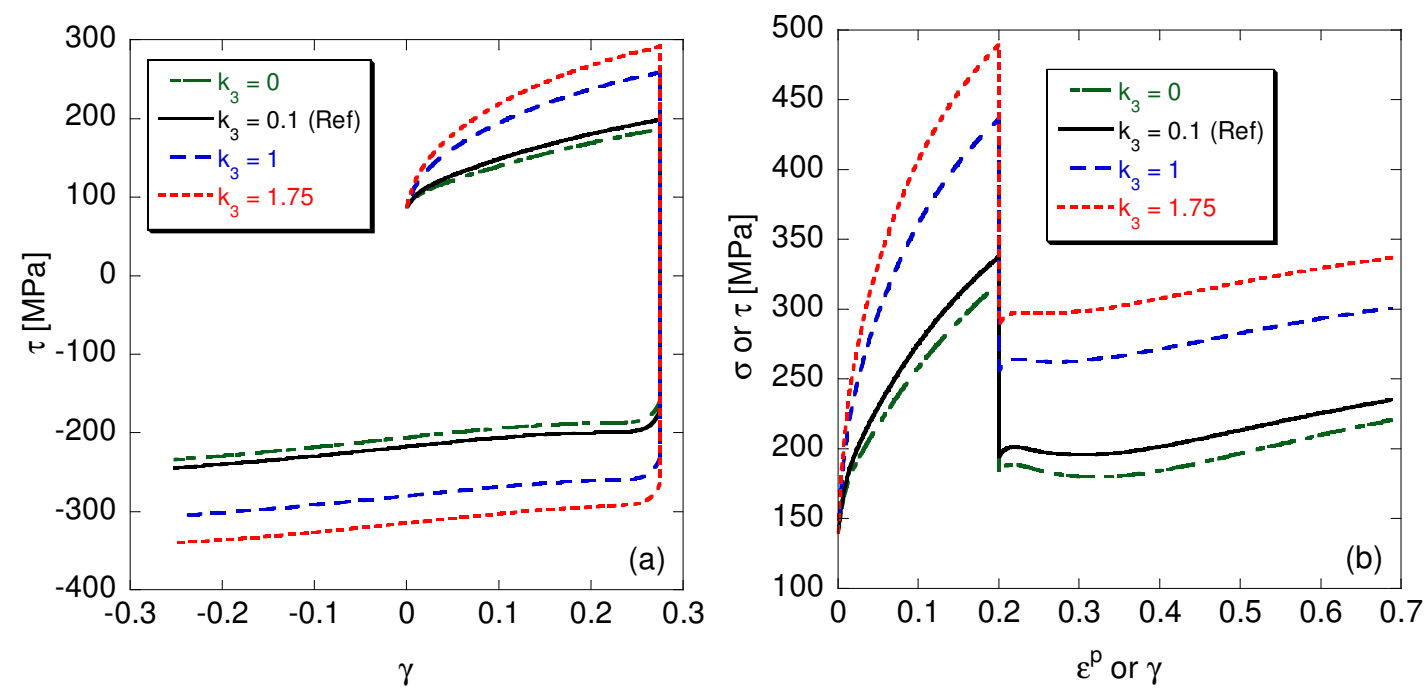

Figure 18. Estimated dynamic recovery effect on work-hardening for IF steel with grain size $D_{F}=25 \mu \mathrm{m}$ for (a) reverse and (b) orthogonal loadings.

\subsection{Sensitivity to parameter $p$}

The polarity parameter $p(0 \leq p \leq 1)$ only intervenes during reverse loading and was introduced to consider that a fraction $p$ of the previously stored dislocation densities is sensitive to the direction of the stress tensor and may gradually disappear when the stress sign is changed. This material parameter has a "temporary" effect (i.e. the first stages of reversing the stress or strain direction; see Figure 19) and influences the work-hardening stagnation. Increasing $p$ enhances work-hardening stagnation. Low carbon steels reveal important workhardening stagnation and therefore a polarity parameter $p$ close to 1 (e.g. $p=0.8$ ). Materials without important work-hardening stagnation (e.g. aluminum alloy AA6022-T4) have a low polarity parameter value (e.g. $p=0.3$ ) [Rauch et al., 2007]. 


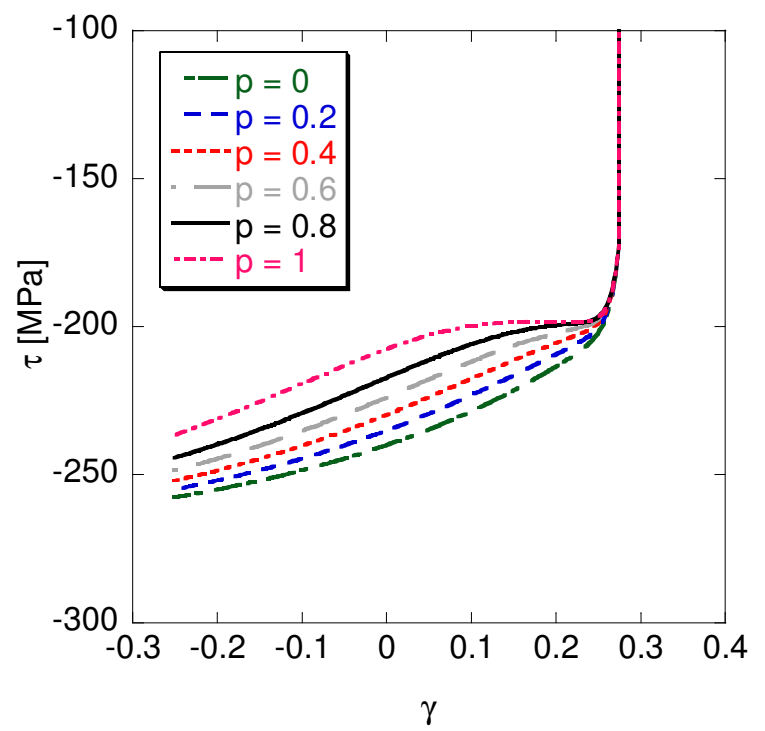

Figure 19. Estimated polarity parameter effect on work-hardening for IF steel with grain size $D_{F}=25 \mu \mathrm{m}$ for reverse loading.

\subsection{Sensitivity to parameter $\lambda$}

The material parameter $\lambda$ stands for the spacing between DWs (or GNBs) and can also be considered as the cell size. $\lambda$ decreases with strain, although in this work we opted to use a constant $\lambda$ value based on experimental observations [Korzekwa et al., 1984], [Uenishi, 2003 ] assuring that a final dislocation structure controlling dislocation motion is quickly developed and quickly reaches its final value. Uenishi et al. [2005] and Li et al. [2004] experimentally noticed that DWs spacing may vary in the $200-1200 \mathrm{~nm}$ range for IF steels while according to Korzekwa et al. [1984], these values may scatter in the 400-700 nm range for DP steels. Numerically, Bergström et al. [2010] found that the final dislocation mean free path is around $\sim 300-600 \mathrm{~nm}$. Note however that $\lambda$ has a much localized effect in this model and basically affects the work-hardening transient regime by changing the initial slope of the stress-strain curve (see Figure 20). In order to go further into the details, because the grain size effect vanishes with strain (i.e. phenomena that were occurring at the grain scale at low strain, now occur at the GNBs or DWs scale), it would be more physically accurate to take into account the evolution of the DWs spacing $\lambda$ instead of grain size $D_{F}$ in Eq. (13).

Yalcinkaya et al. [2009] developed a model to depict cell size evolution (corresponding to $\lambda$ evolution) when strain-path changes occur. By doing this way, the saturation value $X_{\text {sat }}$ would evolve with strain. 

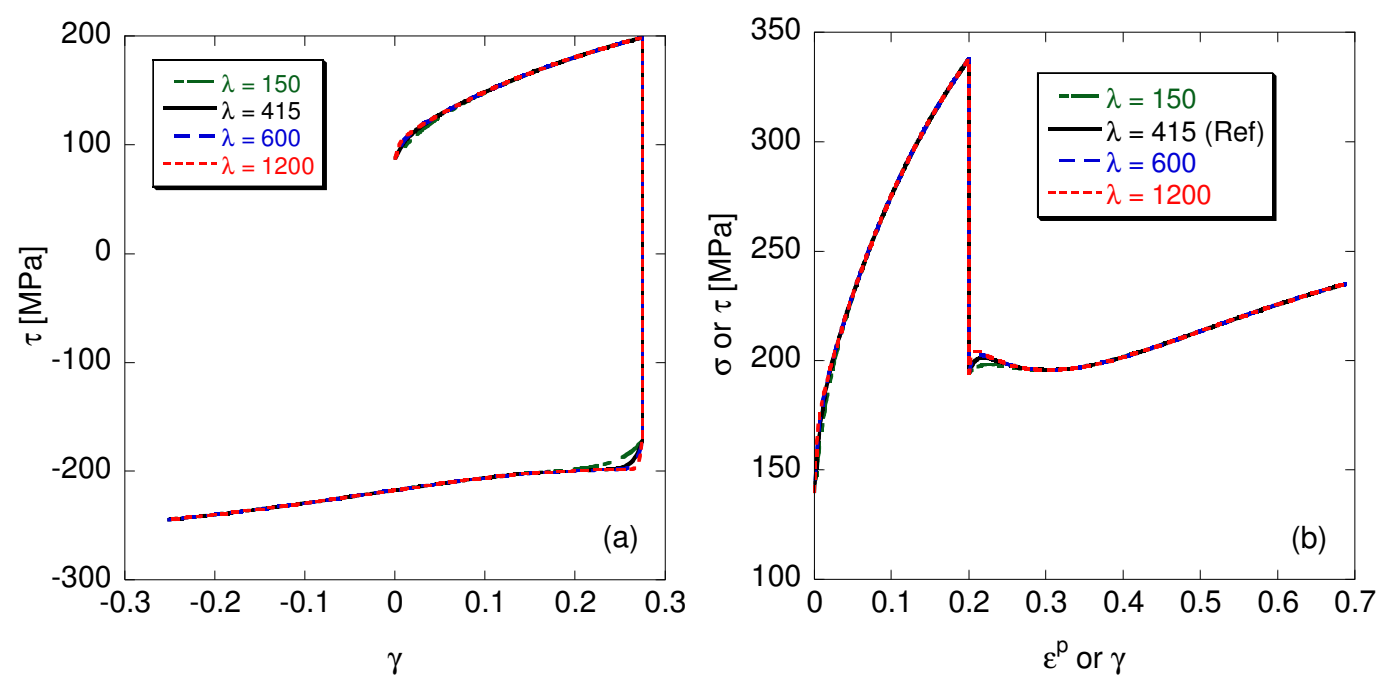

Figure 20. Estimated DWs spacing parameter effect on work-hardening for IF steel with grain size $D_{F}=25 \mu \mathrm{m}$ for (a) reverse and (b) orthogonal loadings.

\subsection{Sensitivity to parameter $\mathbf{n}_{0}$}

$n_{0}$ is the parameter that introduces the concept of internal stress saturation and influences the saturation and rate values of the kinematic work-hardening as well as yield stress at reverse loading (see Figure 21). $n_{0}$ is responsible for describing the Bauschinger effect (yield stress drop at reverse loading). It is important to stand out that recent experimental investigations on B.C.C. metals (microalloyed steels) tend to show that the Bauschinger effect depends on chemical composition and dislocation structure rather than on grain-size [Kostryzhev et al., 2010].
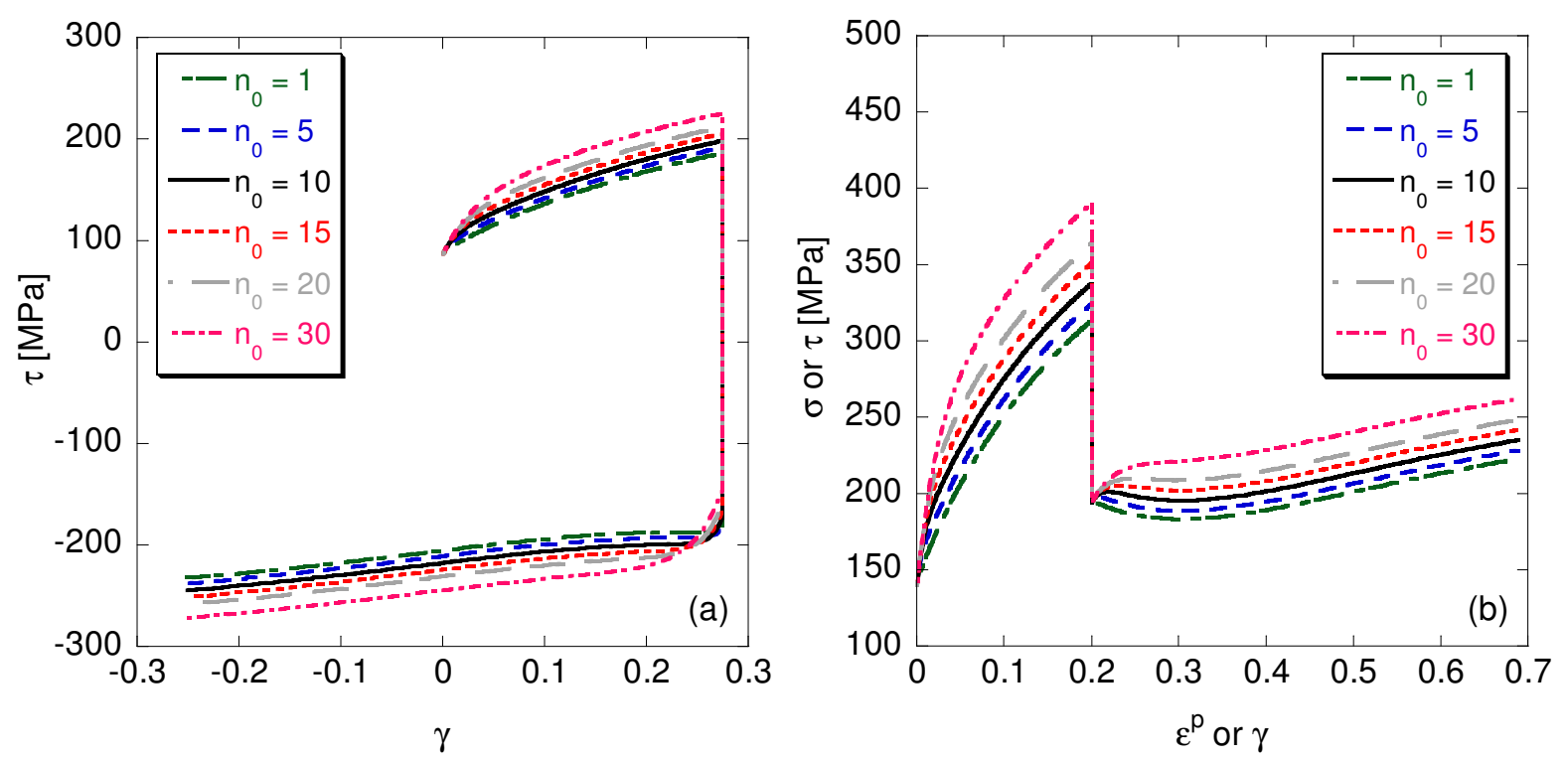

Figure 21. Estimated maximum dislocation "available sites" parameter effect on workhardening for IF steel with grain size $D_{F}=25 \mu \mathrm{m}$ for (a) reverse and (b) orthogonal loadings. 


\subsection{Sensitivity to strain-path change}

For strain-path changes in which only latent dislocations (i.e. $\theta>0$ ) are involved, the strainpath change indicator amplitude is swept between 0 and 1 and the transient regime evolves from softening to nearly monotonic work-hardening, respectively (see Figure 22-a). On the other hand, for strain-path changes in which a mixture of reverse and latent dislocations (i.e., $\theta<0)$ are involved, the strain-path change indicator amplitude is swept between 0 and -1 and the transient regime evolves from softening to work-hardening stagnation (see Figure 22-b).
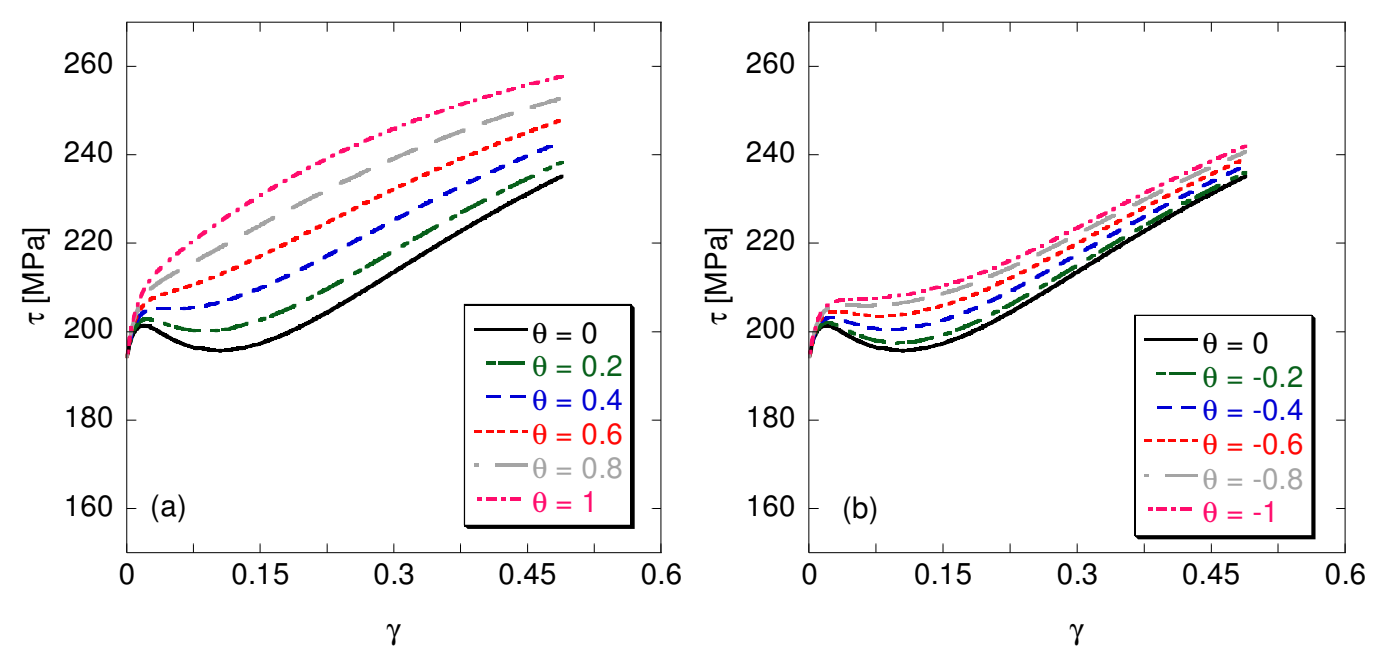

Figure 22. Estimated work-hardening behavior for pre-strained IF steel (after $20 \%$ tensile prestrain) with grain size $D_{F}=25 \mu \mathrm{m}$ in the case of complex strain paths involving (a) orthogonal strain-path change loading, i.e., $\theta>0$ and (b) orthogonal to reverse strain-path change loading, i.e., $\theta<0$.

\subsection{Sensitivity to accumulated strain}

The material model is able to reproduce the evolution of transient regimes and it is seen that the length of the plateau as well as the softening effect increase with the amount of pre-strain for reserve and orthogonal loading, respectively. Such transient behavior is immediately followed by work-hardening resumption as depicted in Figure 23. 

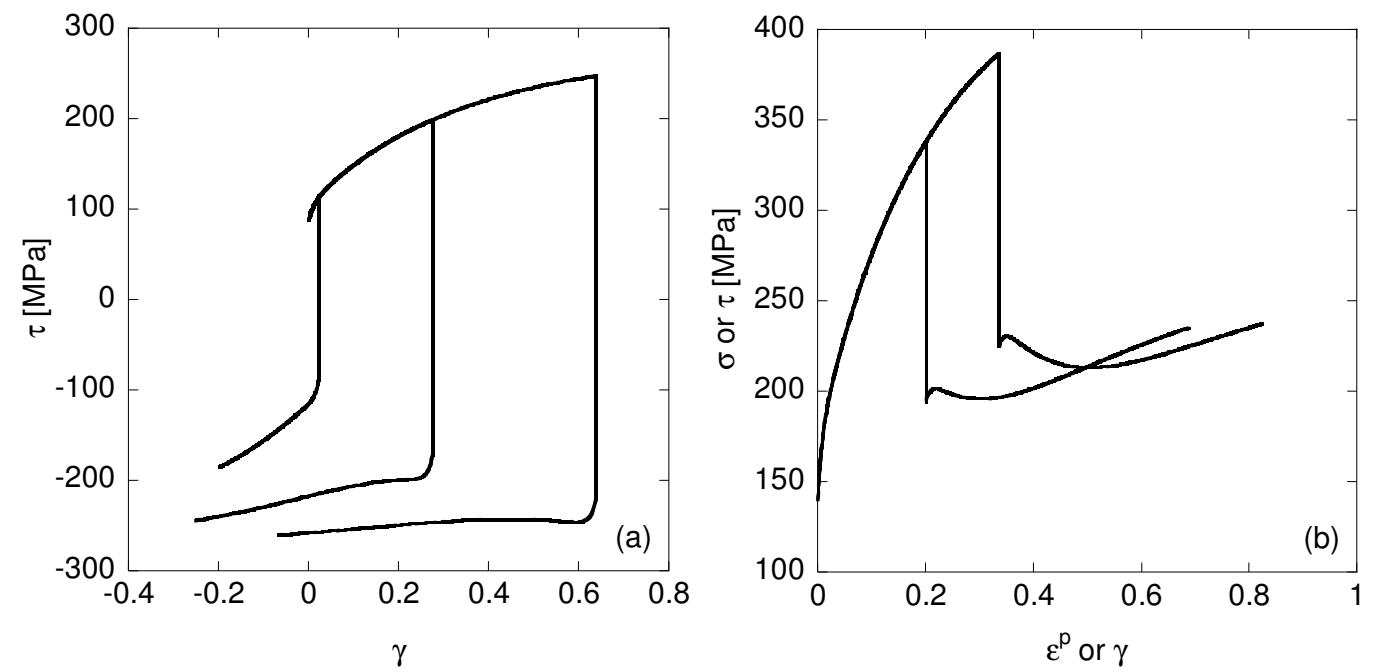

Figure 23. Evolution of (a) work-hardening stagnation and (b) softening with increasing prestrain for IF steel with grain size $D_{F}=25 \mu \mathrm{m}$.

\section{Conclusion}

In this paper, a phenomenological model that incorporates details of the microstructure evolution at the grain-size scale was presented. The intent of this model is to realistically reproduce the experimentally observed work-hardening evolutions during strain-path changes (i.e. Bauschinger effect, work-hardening stagnation, work-softening) that can occur for IF and DP steels. The predictive capabilities of the model are achieved through a set of physicallybased constant parameters $\left(k_{1}, k_{2}, k_{3}, \lambda, n_{0}\right)$, which are specific to metals from the same grade. This parameter set enables the prediction of work-hardening behavior of other metals from the same grade by only modifying the ferrite and martensite mean grain sizes, martensite volume fraction and the chemical composition. Hence, only a single identification procedure is needed for estimating the behavior of other steels from the same grade. In its current version, the model presented in this work includes the following features:

(i) A grain-size dependent [Hill, 1948] yield criterion, which was proposed taking into account the fact that $r$-values are grain-size dependent.

(ii) Chemical composition for the prediction of initial yield stress.

(iii) Three phenomenological dislocation densities that are related to forward, reverse and latent straining. Transient regimes after strain-path change (i.e. work-hardening stagnation and softening) are described through grain-size dependent isotropic hardening based on dislocation density evolution laws proposed by Rauch and co-workers [Rauch et al., 2011].

(iv) A grain-size dependent tensorial expression for kinematic hardening describing the Bauschinger effect.

In the present work, for the sake of simplicity, parameters $k_{1}, k_{2}, k_{3}, \lambda$ and $n_{0}$ were taken as constants. Further work on modeling would consist in introducing their evolution with strain as well as chemical composition dependency. Moreover, it is noteworthy that the main motivation of the present work is rather to define a physically based, simple and accurate 
mathematical form for the stress-strain response of polycrystalline materials that can be easily used in numerical simulations of metal forming processes at room temperature. Further work would then consist of implementing this model in a finite element code in order to simulate industrial forming applications and to capture the significant changes in the formability of the material under continuous strain-path changes during forming processes.

\section{Acknowledgments}

This research has been performed within a project funded by Renault Research Group. The authors gratefully acknowledge Renault for its financial support.

\section{References}

3DS (Digital Die Design System) Report (2001): "Selection and identification of elastoplastic models for the materials used in the benchmarks", 18-month progress report, LPMTMCNRS Université Paris 13, France.

Aouafi A., Bouvier S., Gasperini M., Lemoine X. and Bouaziz O. (2007): "Experimental analysis and modeling of the mechanical behavior of microalloyed steels: Influence of precipitates and correlation with microstructure”, in $10^{\text {th }}$ ESAFORM Conference on Material Forming, Spain.

Armstrong P. J. and Frederick C. O. (1966): "A mathematical representation of the multiaxial Bauschinger effect", Berkeley Nuclear Lab., p. 20.

Barlat F., Gracio J. J., Lee M. G., Rauch E. F. and Vincze G. (2011): "An alternative to kinematic hardening in classical plasticity”, International Journal of Plasticity 27, p. 13091327.

Bergström Y., Granbom Y. and Sterkenburg D. (2010): “A dislocation-based theory for the deformation hardening behavior of DP Steels: Impact of martensite content and ferrite grain size”, Journal of Metallurgy 2010.

Bouaziz O. and Dirras G. (2006): "Effet de taille de grain sur les écrouissages isotrope et cinématique dans la gamme 0,35 à 75 microns”, in Proceedings of Matériaux 2006, November 13-17, France.

Bouquerel J., Verbeken K. and Decooman B. (2006): "Microstructure-based model for the static mechanical behaviour of multiphase steels", Acta Materialia 54 (6), p. 1443-1456.

Bouvier S., Haddadi H., Levée P. and Teodosiu C. (2006a), "Simple shear tests: Experimental techniques and characterization of the plastic anisotropy of rolled sheets at large strains", Journal of Materials Processing Technology 172, p. 96-103.

Bouvier S., Gardey B., Haddadi H. and Teodosiu C. (2006b): "Characterization of the straininduced plastic anisotropy of rolled sheets by using sequences of simple shear and uniaxial tensile tests", Journal of Materials Processing Technology 174, p. 115-126.

Cashform report (2001): "An accurate plasticity model of texture, strain-path induced anisotropy and forming limits for computer-aided sheet metal forming”, Final Technical Report, Cashform Brite-Euram Contract No. BRPR-CT97-0492.

Chaboche J. L. (2008): "A review of some plasticity and viscoplasticity constitutive theories", International Journal of Plasticity 24, p. 1642-1693. 
Chia K. H., Jung K. and Conrad H. (2005): "Dislocation density model for the effect of grain size on the flow stress of a Ti-15.2 at.\% Mo $\beta$-alloy at 4.2-650K”, Materials Science and Engineering A 409, p. 32-38.

Choi Y., Walter M. E., Lee J. K. and Han C. S. (2006): “Observations of anisotropy evolution and identification of plastic spin parameters by uniaxial tensile tests", Journal of Mechanics of Materials and Structures 1 (2), p. 309-331.

Delincé M., Bréchet Y., Embury J. D., Geers M. G. D., Jacques P. J. and Pardoen T. (2007): "Structure-property optimization of ultrafine-grained dual-phase steels using a microstructure-based strain hardening model”, Acta Materialia 55, p. 2337-2350.

Fang X. F. and Dahl W. (1995): "Strain hardening of steels at large strain deformation. Part I: Relationship between strain hardening and microstructures of b.c.c. steels", Materials Science and Engineering A 203, p. 14-25.

Feaugas X. (1999): "On the origin of the tensile flow stress in the stainless steel AISI 316L at 300K: back stress and effective stress", Acta Materialia 47 (13), p. 3617-3632.

Fernandes J. V. and Schmitt J. H. (1983): "Dislocation microstructures in steel during deep drawing”, Philosophical Magazine A, p. 841-870.

Franz G., Abed-Meraim F., Ben Zineb T., Lemoine X., Berveiller M. (2009), "Role of intragranular microstructure development in the macroscopic behaviour of multiphase steels in the context of changing strain paths", Material Science and Engeneering A, 517, p. 300-311.

Gardey B., Bouvier S., Richard V. and Bacroix B. (2005a): "Texture and dislocation structures observation in a dual phase steel under strain-path changes at large deformation”, Materials Science and Engineering A 400-401, p. 136-141.

Gardey B., Bouvier S. and Bacroix B. (2005b): "Correlation between the macroscopic behaviour and the microstructural evolutions during large plastic deformation of a dual phase steel", Metallurgical and Materials Transactions A 36, p. 2937-2945.

Gladman T. (1997): "The physical metallurgy of micro-alloyed steels", The Institute of Materials, London.

Haddadi H., Bouvier S., Banu M., Maier C. and Teodosiu C. (2006), "Towards an accurate description of the anisotropic behaviour of sheet metals under large plastic deformations: Modelling, numerical analysis and identification", International Journal of Plasticity 22, p. 2226-2271).

Hasegawa T. and Yakou T. (1974), "Region of constant flow stress during compression of aluminium polycrystals prestrained by tension”, Scripta Metall. 8, p. 951-954.

Hill R. (1948): "A theory of the yielding and plastic flow of anisotropic metals", Proceedings of the Royal Society A 193, p. 281-297.

Hirsch J. R., Hutchinson W. B. and Lucke K. (1991): "Effect of initial grain size and shape on textures in sheet steel", Textures and Microstructures 14-18, p. 691-696.

Hutchinson B. (1999): "Deformation microstructures and textures in steels", Philosophical Transactions of the Royal Society of London A 357, p. 1471-1485.

Karlyn D. A., Veith R. W. and Forand J. L. (1969): "Effect of decarburization and annealing temperature on plastic anisotropy and grain size in cold rolled low carbon sheet steel", Mechanical Working and Steel Processing VII, The Metallurgical Society AIME, New York, p. 127-130.

Kocks U. F. and Mecking H. (2003): "Physics and phenomenology of strain hardening: the FCC case”, Progress in Materials Science 48, p. 171-273. 
Korzekwa D. A., Matlock D. K. and Krauss G. (1984): "Dislocation Substructure as a Function of Strain in a Dual-Phase Steel”, Metallurgical Transactions A 15, p. 1221-1228.

Kostryzhev A. G., Strangwood M. and Davis C. L. (2010): "Bauschinger Effect in Microalloyed Steels: Part I. Dependence on Dislocation-Particle Interaction”, Metallurgical and Materials Transactions A 41, p. 1399-1408.

Li B. L., Godfrey A., Meng Q. C., Liu Q. and Hansen N. (2004): “Microstructural evolution of IF-steel during cold rolling”, Acta Materialia 52, p. 1069-1081.

Lopes A. B., Barlat F., Gracio J. J., Ferreira Duarte J. and Rauch E. F. (2003): "Effect of texture and microstructure on strain hardening anisotropy for aluminum deformed in uniaxial tension and simple shear", International Journal of Plasticity 19, p. 1-22.

Lücke K. and Hölscher M. (1991): "Rolling and recrystallization textures of BCC steels", Textures and Microstructures 14-18, p. 585-596.

Morrisson W. B. (1966): "The effect of grain size on the stress-strain relationship in low carbon steel", Transactions of the ASM 59, p. 824-846.

Mughrabi H., Ungar T. and Wilkens W. (1986): "Long-range internal stresses and asymmetric $X$-ray line-broadening in tensile-deformed [001]-oriented copper single crystals", Philosophical Magazine A 53(6), p. 793-813.

Mughrabi H. (2006): "Dual role of deformation-induced geometrically necessary dislocations with respect to lattice plane misorientations and/or long-range stresses", Acta Materialia 54, p. 3417-3427.

Murakami K. (2008), "Etude et modélisation des mécanismes de formation des textures de recristallisation dans des aciers Fr-Si”, PhD Thesis, University Paris 13, France.

Nesterova E. V., Bacroix B. and Teodosiu C. (2001a): "Experimental observation of microstructure evolution under strain-path changes in low-carbon IF steel”, Materials Science and Engineering A 309-310, p. 495-499.

Nesterova E. V., Bacroix B. and Teodosiu C. (2001b): "Microstructure and texture evolution under strain-path changes in low-carbon interstitial-free steel”, Metallurgical and Materials Transactions A 32, p. 2527-2538.

Peeters B., Kalidindi S. R., van Houtte P. and Aernoudt E. (2000): “A crystal plasticity based work-hardening/softening model for B.C.C. metals under changing strain paths”, Acta Materialia 48, p. 2123-2133.

Peeters B., Seefeldt M., Teodosiu C., Kalidindi S. R., van Houtte P. and Aernoudt E. (2001a): "Work-hardening/softening of b.c.c. polycrystals during changing strain paths: I. an integrated model based on substructure and texture evolution, and its prediction of the stress-strain behaviour of an IF steel during two-stage strain paths", Acta Materialia 49, p. 1607-1619.

Pickering F. B. (1992): “Constitution of properties of steels”, Ed. F.B. Pickering, Vol. 7 of Materials Science and Technology - A comprehensive treatment Edited by R. W. Cahn, P. Haasen, E. J. Kramer. VCH, Weinheim XVI. 7.

Pipard J. M., Nicaise N., Berbenni S., Bouaziz O. and Berveiller M. (2009): "Mean field micromechanical approach to capture grain size effects", Computational Material Sciences 45, p. 604-610.

Rauch E. F. and Schmitt J. H. (1989): "Dislocation substructures in mild steel deformed in simple shear", Materials Science and Engineering A 113, p. 441-448.

Rauch E. F., Gracio J. J. and Barlat F. (2007): "Work-hardening model for polycrystalline metals under strain reversal at large strains”, Acta Materialia 55, p. 2939-2948. 
Rauch E. F., Gracio J. J., Barlat F. and Vincze G. (2011): “Modelling the plastic behaviour of metals under complex loading conditions", Modelling and Simulation in Materials Science and Engineering 19, p. 1-18.

Renavikar M. P. (2003): "Small strain deformation behavior of Interstitial Free (IF) steels", $\mathrm{PhD}$ thesis, University of Pittsburgh, United States.

Sinclair C. W., Poole W. J. and Bréchet Y. (2006): "A model for the grain size dependent work-hardening of copper”, Scripta Materialia 55, p. 739-742.

Taylor G. I. (1934): "The mechanism of plastic deformation of crystals - Part I: Theoretical”, Proceedings of the Royal Society of London A 145, p. 362-387.

Teodosiu C. and Hu Z. (1995): "Evolution of the intragranular microstructure at moderate and large strains modelling and computational significance”, in: Shen S. F., Dawson, P. R. (Eds.), Proceedings of the International Conference on Numerical Methods in Industrial Forming Processes - Numiform 1995 on Simulation of Materials Processing: Theory, Methods and Applications, p. 173, Rotterdam, The Netherlands.

Thuillier S. and Rauch E. F. (1994): "Development of microbands in mild steel during cross loading", Acta Metallurgica et Materialia 42(6), p. 1973-1983.

Uenishi A. (2003): "Comportement thermodynamique à grandes vitesses de déformation des aciers sans interstitiels à durcissement par solution solide", $\mathrm{PhD}$ thesis, Université Paris 13, France.

Uenishi A. and Teodosiu C. (2003): "Solid solution softening at high strain rates in Si-and/or Mn-added interstitial free steels", Acta Materialia 51, p. 4437-4446.

Uenishi A., Teodosiu C. and Nesterova E. V. (2005): "Microstructural evolution at high strain rates in solution-hardened interstitial free steels", Materials Science and Engineering A 400-401, p. 499-503.

Wilson D. V. and Bate P. S. (1996): "Internal elastic strains in an IF steel following changes in strain path”, Acta Materialia 44 (8), p. 3371-3383.

Winther G. and Jensen D. J. (1997): "Deformation induced dislocation boundaries: Alignment effect on mechanical properties”, Computational Materials Science 9, p. 251260.

Xu P. G., Yin F. X., Huan Y. H., Tomota Y. and Nagai K. (2006): “Texture dedicated grain size dependence of normal anisotropy in low-carbon steel strips”, Materials Science and Engineering A 433, p. 8-17.

Yalcinkaya T., Brekelmans W. A. M. and Geers M. G. D. (2009): "A composite dislocation cell model to describe strain path change effects in BCC metals", Modeling and Simulation in Materials Science and Engineering 17, p. 1-16.

Yoshida F. and Uemori T. (2002): "A model of large-strain cyclic plasticity describing the Bauschinger effect and workhardening stagnation”, International Journal of Mechanical Sciences 18, p. 661-686.

Yoshida F. and Uemori T. (2003): "A model of large-strain cyclic plasticity and its application to springback simulation”, International Journal of Mechanical Sciences 45, p. 1687-1702. 